\title{
Suitability Pre-Assessment of in-Sewer Heat Recovery Sites Combining Energy and Wastewater Perspectives
}

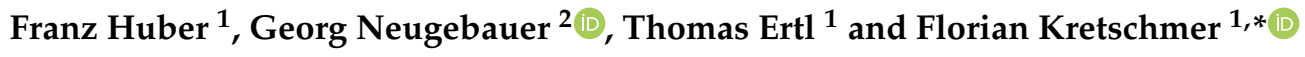 \\ 1 Institute of Sanitary Engineering and Water Pollution Control, University of Natural Resources and \\ Life Sciences, Muthgasse 18, 1190 Vienna, Austria; franz.huber@boku.ac.at (F.H.); \\ thomas.ertl@boku.ac.at (T.E.) \\ 2 Institute of Spatial Planning, Environmental Planning and Land Rearrangement, University of Natural \\ Resources and Life Sciences, Peter Jordan-Strasse 82, 1190 Vienna, Austria; georg.neugebauer@boku.ac.at \\ * Correspondence: florian.kretschmer@boku.ac.at; Tel.: +43-1-47654-81115
}

Received: 5 November 2020; Accepted: 14 December 2020; Published: 17 December 2020

check for updates

\begin{abstract}
In many countries around the world heating (and cooling) has been and will remain the biggest energy sector, but it is still widely dominated by fossil energy sources today. Wastewater as a source of renewable energy contains large amounts of heat and due to its place-bound localization in urban sewer systems it is usually also situated in very close distance to potential heat consumers. However, one has to keep in mind that heat extraction from wastewater might have undesired impacts on temperature-sensitive treatment processes in the related wastewater treatment plant (WWTP). To assess the potential impact of in-sewer heat recovery on inflow temperature, two different approaches are available today: a simple (but less significant) alligation alternate, or very accurate (but less practical) mathematical models. To close the gap between practicability and significance this article introduces a novel approach to pre-assess the suitability of in-sewer heat recovery sites based on little and easily available data considering energy- and wastewater-related perspectives. A case study application demonstrates the informative value and general usability of the approach. Consequently, the proposed procedure can provide guidance and a template for related investigations at any place in a conventional (combined or separated) sewer system.
\end{abstract}

Keywords: climate change; renewable energy; wastewater treatment plant; heat pump; heat exchanger; relevance tree

\section{Introduction}

Climate change is one of the great challenges of our times. In this context, the United Nations [1] demand "access to affordable, reliable, sustainable and modern energy for all" and "urgent action to combat climate change and its impacts" as formulated in their goals for sustainable development. In this regard the climate and energy framework of the European Union [2] defines (i) a cut in greenhouse gas emissions, (ii) an increase in the share of renewable energy and (iii) an improvement in energy efficiency as key targets. Following recent discussions, one might get the impression that they primarily address and highlight the importance of "green" electricity and mobility, respectively; however, "green" heating (and cooling) still appears rather underrepresented in this discourse. This is difficult to understand, because in many countries (of the European Union) this sector already is and will remain the biggest of the three energy sectors [3], which presently is still widely dominated by fossil energy sources (mainly natural gas) [3]. In the search for renewable heat sources, wastewater has attracted increased attention in recent years, culminating in the official acknowledgement of wastewater as a renewable source of energy in a late-breaking recast of the European directive on the promotion of the use of energy from renewable sources [4]. This is due to the fact that wastewater 
contains significant amounts of untapped heat (originating from the use of warm/hot water in domestic, commercial and industrial applications) [5-8].

This thermal energy content of wastewater could be rather easily recovered by the application of a heat exchanger situated in the wastewater flow and a subsequent heat pump installation [9]. In that scenario, wastewater heat recovery could take place at three different locations in the wastewater system [10]: (i) in-house, (ii) in-sewer and (iii) in-effluent at a wastewater treatment plant (WWTP). The latter site provides benefits in terms of high and continuous flow rates of (treated) wastewater, but is frequently linked with disadvantageous energy supply distances due to the remote location of a WWTP in a settlement. For the two former sites, the situation is basically vice-versa, with lower and discontinuous (untreated) wastewater flows but typically closer supply distances to potential energy consumers. However, apart from these more energy(-economical) considerations, one has also to be aware of one major drawback related to wastewater treatment and water pollution control, namely, a possible impact of in-sewer heat extraction on temperature-sensitive treatment processes in WWTPs situated downstream [11]. In this context one must recall that the main objectives of wastewater systems are the protection of human health (community hygiene and urban flood control) and (receiving) water pollution control [12]. However, this should not totally preclude wastewater heat recovery, although it may limit it to appropriate locations. To tackle the challenge of predicting/evaluating the (possible) effects of in-sewer heat recovery on the inflow temperature of a WWTP, the current literature proposes two approaches: (i) a common alligation alternate, which provides an expected wastewater temperature decrease at the WWTP by simply opposing expected wastewater temperature decreases and flow rates at the heat recovery site and the wastewater flow rate in the influent of the related WWTP [13], or (ii) different mathematical modelling approaches, such as the very holistic concept in the Swiss TEMPEST model [14], which inspired the development of the more parsimonious Dutch model [15]. A less data-intensive concept was also developed in England [16], which was later used for integration into the hydrodynamic SWMM model (Storm Water Management Model) conducted in Austria [17], as well as two Swedish developments, one focusing primarily on the property level of a wastewater system [18], the other with a more system-wide perspective [19]. Concluding, the former approach of the alligation alternate is rather easy to apply but tends to overestimate the actual impact. The latter modelling concepts tend to be more accurate in predicting potential temperature changes, but their practicability suffers from a multitude of required input data for model set-up and calibration.

Although both approaches have their strengths, they do not appear particularly suitable for a quick and conclusive first identification and pre-assessment of the most promising in-sewer heat recovery sites in a settlement (and are better recommended for subsequent and more detailed investigations). To support the closure of the existing gap between significance and practicability, this article introduces a novel approach to pre-assess the suitability of in-sewer heat recovery sites by applying the method of relevance trees considering both energetic and wastewater perspectives. This work is based on the following research questions: (i) what thematic categories are relevant for the pre-assessment of in-sewer heat recovery sites, (ii) what (measurable) criteria can be used to evaluate these categories and (iii) how can these categories and criteria, respectively, be joined in a structural and logical context to provide a clear working flow for the pre-assessment procedure. Besides the theoretical framework, the practical application of the developed approach is presented with a case study.

\section{Materials and Methods}

\subsection{Theory Framework}

The presented suitability pre-assessment of in-sewer heat recovery sites is based on the relevance tree method. This is an evaluation method that is used in environmental planning for the ordinal classification of investigated planning options/scenarios according to the subsequent queries of different assessment categories/indicators. This approach enables the analysis, simplification and evaluation of complex systems as well as the preparation of transparent and comprehensible decision-making 
processes [20]. Hereby, pre-defined categories and assigned assessment criteria, respectively, are structured and visualized in a network (tree) that is structured in a hierarchical order (the more important, the higher ranked the category/criteria). The creation of a relevance tree is done in several steps $[20,21]$. In the first step, the characteristics are listed according to their importance (the more important, the higher ranked), followed by classification of the characteristics (e.g., yes/no, threshold values). In a further step, the number of classes/grades of the ordinal scale are determined, and finally the characteristics are assigned classes/grades (value ranges). Every situation under consideration that has certain combinations of attributes can be assigned to a certain class in a transparent way.

An advantage of this method is that the classification is objectively justified, and the evaluation determined by the construction of the relevance tree (sequence of criteria, type of branching) is expressed transparently and clearly [21]. However, the decomposition of complex issues can also represent a disadvantage if a holistic view is neglected [20].

\subsection{Pre-Assessment Procedure Development}

To develop the framework of the relevance tree, relevant aspects related to in-sewer heat recovery are collected and summarized in conclusive categories. To guarantee a comprehensive view, this working step considers two perspectives: one related to energy and one related to wastewater. These categories define not only the conceptual orientation in the pre-assessment procedure but also provide, in a second step, the framework for the definition of related pre-assessment criteria. These criteria allow a qualitative and/or quantitative evaluation of the defined categories, and thus provide the decision basis for the actual pre-assessment. However, to complete the entire procedure, the defined categories/criteria must be organized in a (relevance) tree structure considering a specific hierarchical order. The entire pre-assessment procedure will be applied in a case study to demonstrate its practicability.

The definition of relevant categories is based on a detailed review of three different literature sources: (i) a Swiss guideline for the planning, approval and implementation of wastewater heat recovery systems [22]; (ii) an Austrian information brochure summarizing the key outcomes of two national research projects concerning wastewater heat recovery and the integration of wastewater-based energy into local energy supply concepts [23]; and (iii) a German guideline on wastewater heat recovery [24]. We consider the limitation of the used materials to selected literature in the German language justified for two reasons. On the one hand, these three countries already have many years of practical experience in the field of wastewater heat recovery. On the other hand, some of the key contents of this literature will thus be made available for the international, mainly English-speaking community.

Figure 1 summarizes the different steps needed to develop the pre-assessment procedure.

The collection of relevant aspects and their categorization is done in four subsequent steps: (i) the above presented materials are screened for key aspects described in connection with in-sewer heat recovery; (ii) the identified aspects are transferred into a table where each column represents one of the three literature sources, and the aspects of equal or comparable characteristics/meaning are placed side by side along the same line; (iii) the contents of each line are summarized under a thematic umbrella term (conclusive category) displayed in the fourth and last column of the table; and (iv) the categories are grouped according to their primary relevance to an in-sewer heat recovery site via either their "energy-related potential" or "wastewater-related vulnerability". This differentiation particularly serves information purposes and supports the later structuring of the relevance tree.

The definition of pre-assessment criteria for each category is, again, made in three subsequent steps: (i) the above-presented materials are screened a second time, but now in the context of the different categories; (ii) threshold values, minimum requirements, restrictions, and so on that have been quoted in the literature are summarized in a new table where the different lines represent the specific categories and the columns represent the original materials; and (iii) the apparent most suitable pre-assessment criterion for each line is derived and displayed in the fourth and last column of the table. 
Those categories still lacking an appropriate criterion after the screening of the presented materials require a review of additional literature sources.

The set-up of categories/criteria in a relevance tree structure follows the approach described in [20] made up of three subsequent steps. Firstly, all categories are brought into a hierarchical order wherein the ranking of categories is based on their specific significance and importance to in-sewer wastewater heat recovery (planning), while also considering the logical structure of the query procedure. In addition, the categories are grouped according to their relevance to the investigated site in regards to "energy-related potential" or "wastewater-related vulnerability". Following the hierarchical order of the categories, the related criteria are integrated in a (relevance) tree structure. Based on the structure of the criteria, suitability levels are introduced at the "root" of the (relevance) tree representing the pre-assessment results.

To demonstrate its practicability, the developed pre-assessment procedure is applied in a case study.

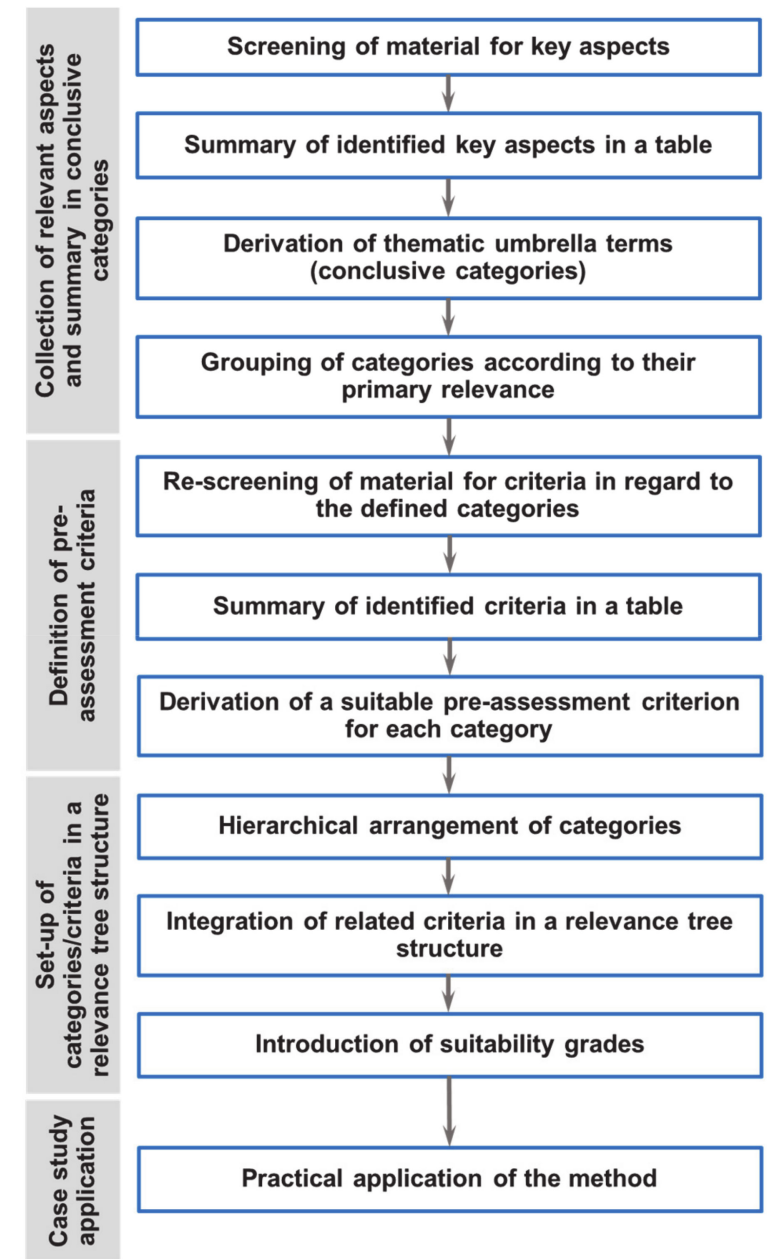

Figure 1. Steps for developing the pre-assessment procedure (own presentation).

\subsection{Case Study Site}

The case study site was situated in a rural Austrian village of around 2500 inhabitants. It is a growing regional center, and consequently serves not only residential purposes but also provides a location for notable commercial sites, various schools, a main hospital and so on. The related sewer system also serves neighboring settlements.

The designated in-sewer heat recovery site was located in a peripheral area of the settlement with mixed structural functions (commercial, schooling, recreation). Consequently, possible heat consumers were manifold in the area. The applicability of the pre-assessment procedure will be demonstrated 
using an existing school building (estimated heated area of $5000 \mathrm{~m}^{2}$ with an assumed energy demand of $\left.100 \mathrm{kWh} / \mathrm{m}^{2 *} \mathrm{a}\right)$.

Without intentionally anticipating any results regarding the derivation of categories relevant for in-sewer heat recovery, one can say that the wastewater flow rate at the intended site was of crucial importance. For a simple and less data-extensive pre-assessment, we suggest estimating the flow rate based on connected population and commercial/industrial sites (population equivalents (PEs)). However, in the context of the presented case study, short-term in-sewer measurements were carried out by a local consultant [25] on behalf of the wastewater utility in June 2020. Consequently, we directly used the following (rough) information collected on wastewater flow and wastewater temperature:

- measurement point (MP) 1: dry weather flow of around 30-40 L/s and about $19{ }^{\circ} \mathrm{C}$

- measurement point (MP) 2: dry weather flow of around $20-30 \mathrm{~L} / \mathrm{s}$ and about $18^{\circ} \mathrm{C}$

- measurement point (MP) 3: dry weather flow of about $5 \mathrm{~L} / \mathrm{s}$ and about $19^{\circ} \mathrm{C}$

Figure 2 provides an overview of the designated in-sewer heat recovery site.

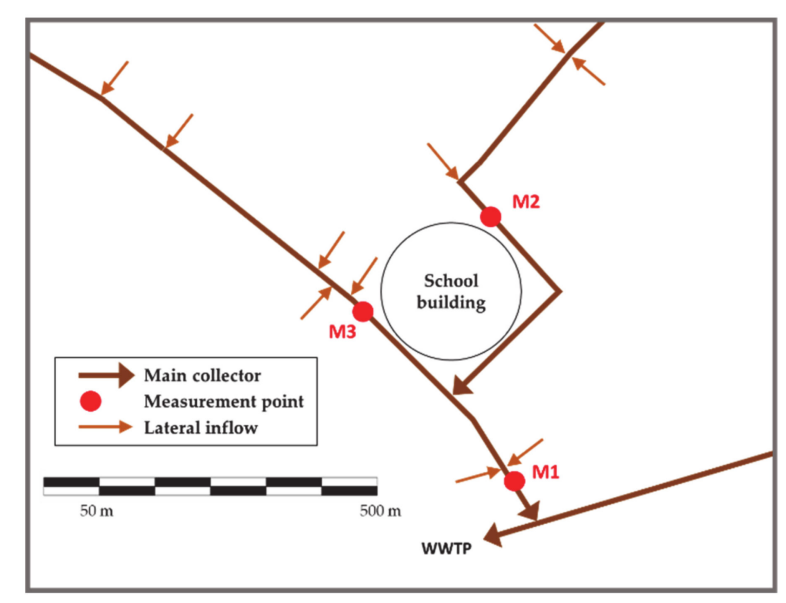

Figure 2. Location of the designated heat recovery site (own representation).

Wastewater collection was based on a separated system. The related WWTP was situated around $10 \mathrm{~km}$ downstream. Its current capacity comprises 37,500 population equivalents (PEs), with an average load of around 20,000 PEs. Dry weather flow was between 3000 to $4000 \mathrm{~m}^{3} / \mathrm{d}$ (around 35 to $45 \mathrm{~L} / \mathrm{s}$ ). The wastewater temperature in December 2019 was slightly above $8^{\circ} \mathrm{C}$, while in September 2020 the average temperature was around $15^{\circ} \mathrm{C}[26]$.

\section{Results}

\subsection{Energy- and Wastewater-Related Categories}

The review of the three mentioned documents resulted in the deduction of eight different thematic categories determined to be relevant for in-sewer heat recovery and suitability (pre-) assessment.

To describe the "energy-related potential" at an in-sewer heat recovery site, the following four categories were determined to be of relevance:

- Heat demand: The heat demand/consumption of an intended supply site is a key factor as it defines the technical and economic boundary conditions of the intended heat supply system [22-24].

- Supply distance: The supply distance between the sites of heat recovery and heat demand/consumption and the related transportation heat loss, respectively, limit the economic feasibility of an in-sewer heat supply system $[23,24]$. Otherwise, if the point of heat consumption is in close vicinity to the local WWTP, heat recovery from the effluent might even be more favorable compared to in-sewer heat recovery [23]. 
- Wastewater flow rate: The dry weather wastewater flow (depending on the PEs connected upstream) at the intended in-sewer heat recovery site determines the available heat recovery potential [22-24]. In this context it should be mentioned that wastewater temperature during dry weather also plays an important role. However, this parameter cannot be derived from easily accessible sources (such as connected PEs) but must be measured, and thus requires more effort for data collection. For this reason, we did not consider wastewater temperature in our pre-assessment procedure. However, as stated in the discussion section of this article, in-sewer measurements are recommended as a subsequent investigation step for locations that appear promising after the pre-assessment. In this context it is also necessary to mention that due to the possible seasonal variation of wastewater flow and temperature measurement, campaigns are recommended to be carried out during the heating period.

- Operating hours: Long-term heat demand/consumption (all-day, year-round) is related to the continuous and thus more economic operation of a heat recovery system $[23,24]$.

The additional four categories concerned the "wastewater-related vulnerability" of an in-sewer heat recovery site:

- Wastewater temperature-related requirements/constraints: The main purpose of a WWTP is water pollution control. The performance of wastewater treatment and especially nitrogen removal efficiency strongly depends on wastewater temperature. Related threshold values are defined according to national laws/guidelines prohibiting in-sewer heat recovery from interfering with the protection of the receiving waters $[23,24]$.

- Share of total wastewater flow: The wastewater flow at the intended in-sewer heat recovery site compared to the total flow at the influent of the WWTP is related to the expectable heat-extraction impact (cooling) on the influent of the WWTP. The lower the share of the flow at the intended in-sewer heat recovery site, the less significant the possible impact of heat extraction on the wastewater temperature at the inflow of a WWTP. This is important in regard to the temperature-sensitive processes in a WWTP [22-24].

- Remaining flow distance: Wastewater temperature reduction due to in-sewer heat extraction might be (partly) compensated along the remaining flow distance towards the WWTP $[23,24]$.

- Sewer operation and maintenance: The main purpose of a sewer system is community hygiene and urban flood protection. Installation and operation of in-sewer heat recovery facilities may not adversely influence the functionality of the sewer system [22-24].

\subsection{Selection of Assessment Criteria}

To quantify and thus pre-assess the presented categories, related criteria were derived from the defined material and, where necessary, from additional literature, respectively.

\subsubsection{Heat Demand}

Concerning the heat demand of the intended supply site [22,23], $100 \mathrm{~kW}$ was determined to be the minimum requirement (for economic feasibility). Consequently, we defined this heat demand as an initial value. To allow a more differentiated pre-assessment, we introduced a gradual increase up to a maximum level of $300 \mathrm{~kW}$. We considered this range appropriate for single object investigations (administrative buildings, schools, etc.). Ultimately, the following heat-demand criteria were included in the pre-assessment method: 100, 125, 150, 175, 200, 225, 250, 275 and $300 \mathrm{~kW}$.

\subsubsection{Supply Distance}

In regard to the supply distance between the sites of heat recovery and heat demand, practical experience [27] has revealed a rather proportional correlation between supply distance and heat demand, where the (economically feasible) supply distance directly increases with the supplied heat demand. Table 1 summarizes the supply distance criteria applied in the pre-assessment method. 
Table 1. Heat supply distances depending on supplied heat demand (own representation, based on [28]).

\begin{tabular}{cc}
\hline Heat Demand (kW) & Bridgeable Supply Distance $(\mathbf{m})$ \\
\hline 100 & $\leq 100$ \\
\hline 125 & $\leq 125$ \\
\hline 150 & $\leq 150$ \\
\hline 175 & $\leq 175$ \\
\hline 200 & $\leq 200$ \\
\hline 225 & $\leq 225$ \\
\hline 250 & $\leq 250$ \\
\hline 275 & $\leq 275$ \\
\hline 300 & $\leq 300$ \\
\hline
\end{tabular}

In addition, we also considered the spatial context between the location of the heat consumption and the WWTP to be a supply distance criterion (distance between heat demand and WWTP). This is justified by the fact that, for consumption points in the close vicinity of a WWTP (e.g., within $1 \mathrm{~km}$ ), heat supply from the effluent is considered more favorable compared to an in-sewer heat extraction. [7,23].

\subsubsection{Wastewater Flow Rate}

The dry weather wastewater flow rate at the investigated in-sewer site is an important parameter, as it defines heat content/potential in the wastewater. It therefore stands in close relation to the heat supply potential and the required heat extraction or degree of wastewater cooling, respectively.

Equation (1) [24] provides the wastewater heat extraction at the intended in-sewer heat recovery site $P_{R S}$ based on the heat demand supplied by the heat pump $P_{\mathrm{HP}}$ at a certain heat pump's coefficient of performance (COP). In our case, this value was assumed to be 5 , indicating that a heat demand of $5 \mathrm{~kW}$ required $4 \mathrm{~kW}$ of thermal energy from the wastewater and $1 \mathrm{~kW}$ of electric energy from the grid to run the heat pump.

$$
\mathrm{P}_{\mathrm{RS}}=\frac{\mathrm{P}_{\mathrm{HP}}}{\left(\frac{\mathrm{COP}}{\mathrm{COP}-1}\right)}
$$

$\mathrm{P}_{\mathrm{RS}}=$ Wastewater heat extraction $[\mathrm{kW}]$

$\mathrm{P}_{\mathrm{HP}}=$ Supplied heat demand $[\mathrm{kW}]$

$\mathrm{COP}=$ Coefficient of performance $=5$

Equation (2) [24] shows the required heat extraction at the designated in-sewer heat recovery site $\Delta \mathrm{T}_{\mathrm{RS}}$ depending on the actual dry weather wastewater flow rate $\left(\mathrm{Q}_{\mathrm{RS}}\right)$ and the intended wastewater heat extraction $\left(\mathrm{P}_{\mathrm{RS}}\right)$ (also considering the specific heat capacity of (waste)water (c)). As a result, the required extraction could also be interpreted as the expected drop of the wastewater temperature at the investigated site.

$$
\Delta \mathrm{T}_{\mathrm{RS}}=\frac{\mathrm{P}_{\mathrm{RS}}}{\mathrm{Q}_{\mathrm{RS}} * \mathrm{c}}
$$

$\Delta \mathrm{T}_{\mathrm{RS}}=$ Wastewater heat extraction $[\mathrm{K}]$

$\mathrm{QRS}_{\mathrm{RS}}=$ Wastewater flow rate (dry weather) $[\mathrm{L} / \mathrm{s}]$

$\mathrm{c}=$ Specific heat capacity of $4.2 \mathrm{~kJ} / \mathrm{kg}^{*} \mathrm{~K}$ (or $1.16 \mathrm{kWh} / \mathrm{m}^{3 *} \mathrm{~K}$ )

The application of both equations provides information on (required) wastewater heat-extraction levels depending on the applied heat demand and actual dry weather wastewater flow rate at the investigated in-sewer site. Concerning the latter, [22-24] have suggested a minimum quantity of $10 \mathrm{~L} / \mathrm{s}$ 
of (average) dry weather flow, which we defined as a base value in our procedure. Concerning the former, we referred to the already-mentioned heat-demand criteria (levels). Combining both aspects, Table 2 differentiates (arithmetic values of) wastewater heat-extraction levels in four ranges $(<2.0,<1.0$, $<0.5$ and $<0.25 \mathrm{~K}$ ) depending on different heat demands and dry weather wastewater flows.

Table 2. Wastewater flow rate criteria (own representation, based on [28]).

\begin{tabular}{ccccc}
\hline Heat Demand $\mathbf{P}_{\mathbf{H P}} \mathbf{( k W )}$ & \multicolumn{4}{c}{ Dry Weather Wastewater Flow Rate $\mathbf{Q}_{\mathbf{R S}}$ (L/s) } \\
\hline 100 & $\geq 10$ & $\geq 20$ & $\geq 40$ & $\geq 80$ \\
\hline 125 & $\geq 12.5$ & $\geq 25$ & $\geq 50$ & $\geq 100$ \\
\hline 150 & $\geq 15$ & $\geq 30$ & $\geq 60$ & $\geq 120$ \\
\hline 175 & $\geq 17.5$ & $\geq 35$ & $\geq 70$ & $\geq 140$ \\
\hline 200 & $\geq 20$ & $\geq 40$ & $\geq 80$ & $\geq 160$ \\
\hline 225 & $\geq 22.5$ & $\geq 45$ & $\geq 90$ & $\geq 180$ \\
\hline 250 & $\geq 25$ & $\geq 50$ & $\geq 100$ & $\geq 200$ \\
\hline 275 & $\geq 27.5$ & $\geq 55$ & $\geq 110$ & $\geq 220$ \\
\hline 300 & $\geq 30$ & $\geq 60$ & $\geq 120$ & $\geq 240$ \\
\hline Heat extraction $\Delta \mathrm{T}_{\mathrm{RS}}(\mathrm{K})$ (rounded) & $<2.0$ & $<1.0$ & $<0.5$ & $<0.25$ \\
\hline
\end{tabular}

\subsubsection{Operating Hours}

The higher the operating hours of a heat supply system (heat pump), the more efficient it can be operated from an economic point of view [22-24]. According to [7], mixed settlement structures combining residential and commercial uses (offices, etc.) appear very promising as they combine different diurnal heat-demand curves, leading to specific operating hours of the heat supply system of up to 4500 full load hours. However, for simple mono-structural uses such as in residences, 1500-2200 full load hours are common figures (at least for Central Europe). Based on these requirements, we considered the distinguishing criterion in our approach to be 2200 operating hours per year.

\subsubsection{Wastewater Temperature-Related Requirements/Constraints}

As already stated before, wastewater temperature-related requirements/constraints in a WWTP primarily concern the processes of nitrogen removal. In our article we consider Austrian national regulations, although our suggested approach can also be easily adapted to other national concepts. The Austrian regulation on wastewater emissions from municipal WWTPs [29] defines nitrogen removal efficiency (denitrification) threshold values as well as maximum ammonia concentrations in the effluent (nitrification) that are dependent on the size of a WWTP. In general, the former is obligatory for wastewater temperatures beyond $12{ }^{\circ} \mathrm{C}$, while the latter is required for wastewater temperatures beyond $8{ }^{\circ} \mathrm{C}$. In our approach, we accordingly set a wastewater temperature of $8{ }^{\circ} \mathrm{C}$ at the inflow of a WWTP as a minimum requirement. The $12{ }^{\circ} \mathrm{C}$ threshold was also used as an additional distinguishing criterion.

\subsubsection{Share of Total Wastewater Flow}

The share/proportion of wastewater flow at the intended in-sewer heat recovery site (partial wastewater flow rate) compared to the total wastewater flow at the inflow of the related WWTP provides an idea of the impacts of heat extraction that can be expected on the inflow temperature of a WWTP. Ref. [13] presents a simple method for estimating the effects of in-sewer heat recovery on the inflow temperature of WWTPs based on a simple alligation alternate. Figure 3 graphically applies this approach (using theoretical heat-extraction levels of 0.25 and $1.00 \mathrm{~K}$ ), indicating that smaller partial wastewater flow rates $\left(\mathrm{Q}_{\mathrm{RS}} / \mathrm{Q}_{\mathrm{WWTP}}\right)$ imply lower expected decreases in inflow temperature. 
For the differentiated pre-assessment of intended heat recovery sites, our approach distinguishes two shares of total wastewater flow as representative of the pre-assessment: $\leq 0.25$ and $\leq 0.5$. In the context of wastewater temperature change one should also mention that [24] considered a decrease of up to $0.5 \mathrm{~K}$ in the influent of the WWTPs not critical. Although we do not agree with this assumption as a general definition (from an Austrian perspective, related temperature drops at WWTPs with inflow temperatures around 12 or $8{ }^{\circ} \mathrm{C}$ are critical), it can be supportive in the pre-assessment, at least to a certain extend. This is because it defines a kind of reference value for interpreting heat-extraction levels (in Table 2) from a more wastewater-related perspective.

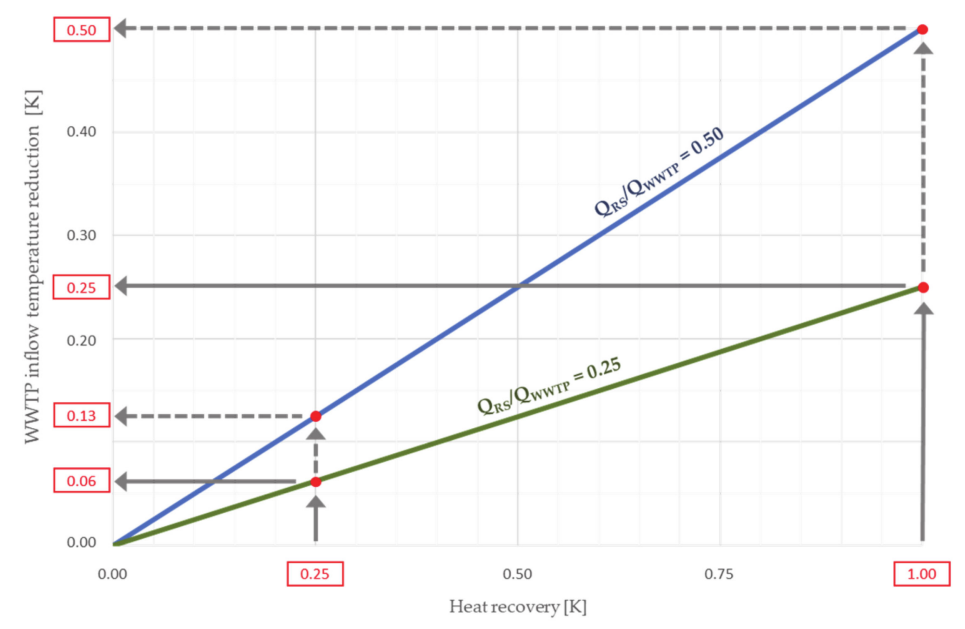

Figure 3. Heat recovery/temperature reduction relationship (own representation, based on [13]).

\subsubsection{Remaining Flow Distance}

The modelling approaches presented in the introduction section of this article aim to predict wastewater temperature (changes) along an in-sewer flow path. This approach is considered rather complex, as it requires input data of various temperature influences (e.g., soil temperature, in-sewer air temperature, lateral inflows). The longer the remaining flow distance, the more temperature-sensitive wastewater aspects have to be taken into account. Consequently, one could assume that heat extraction might even be (partly) compensated along the remaining flow path. Ref. [30] showed a network in Germany in which the wastewater temperature condition was rather stable along the sewer system. Ref. [13] observed an Austrian sewer system where in-sewer wastewater temperatures seemed to adapt to a steady-state condition within a rather short flow distance. Ref. [31] reported comparable observations from one city in Italy. In addition, modelling results in [32] revealed rather low decreases in wastewater temperature along the flow path (e.g., about $0.2 \mathrm{~K}$ for wastewater of $10{ }^{\circ} \mathrm{C}$ along a flow distance of $10 \mathrm{~km}$ ). Although these observations may not have a general validity due to the vast amount of site-specific influences, they still support the assumption that heat extraction could be (partly) compensated for along the remaining flow distance to the WWTP. In our approach we set the distinguishing flow distance to $5000 \mathrm{~m}$ (as $1000 \mathrm{~m}$ has already been addressed in the "supply distance" criterion, and the 10,000 $\mathrm{m}$ from [32] appears to exceed the dimensions of many sewer systems).

\subsubsection{Sewer Operation and Maintenance}

Heat exchangers situated in the main flow of a sewer system might reduce hydraulic capacity and complicate the different tasks of sewer operation and maintenance (e.g., cleaning, inspection, rehabilitation). Also, the installation and maintenance work of a heat exchanger may not interfere with the proper functioning of the wastewater system. In-sewer wastewater heat recovery in a bypass helps to avoid these problems (although these solutions consume more space and have a higher cost). Our pre-assessment procedure addresses this issue by asking whether a bypass installation is possible or not, but it only addresses the basic technical and spatial boundary conditions. Economic aspects 
(e.g., minimum heat demand) require additional investigation at locations that appear promising after the pre-assessment.

\subsection{Method for Suitability Pre-Assessment}

To establish the method/procedure for pre-assessment of in-sewer heat recovery sites, the presented categories and their related criteria, respectively, will be joined in a (relevance) tree structure basically interlinked by simple yes/no queries. Their arrangement follows a hierarchical order mainly based on the assumed significance and importance of each category, but also considering logical query structures and the easy availability of data in regard to specific criteria. To provide a better orientation for the user, the tree is divided into two thematic sections: the upper part of the tree addresses the energy-related potential, the lower part the wastewater-related vulnerability. Figure 4 provides an overview of the relevance tree structure. This illustration aims to explain the practical applications of the procedure from a more theoretic point of view.

For the pre-assessment of in-sewer heat recovery sites in general, and concerning the energy-related potential in particular, we consider the (expected) "heat demand" to be the most important category, as it defines the boundaries of the intended supply system. Consequently, it is the starting point of the entire approach, and thus symbolically framed in bold. In the presented overview, the criterion value is left blank, while the relevance trees of practical applicability for the nine different energy demands defined in Section 3.2.1 (range from 100 to $300 \mathrm{~kW}$ ) can be found in Appendix A of this article.

The next query concerns the "operating hours" of the intended heat supply system. From a hierarchical point of view, this aspect might be addressed later, but due to its close relation to heat demand it is related here for logical reasons. As discussed in Section 3.2.4, our approach applies a distinguishing value of $2200 \mathrm{~h}$ per year. Operating hours below this value are considered a knock-out criterion in our approach.

The following queries address the "supply distance" category. The distance between the heat demand and the WWTP is important, as a distance below a certain range (in Section 3.2.2 we defined it as $1000 \mathrm{~m}$ ) indicates the effluent of a WWTP to be more favorable compared to an in-sewer application. As presented in Table 1, the (bridgeable) distance between the heat recovery site and the site of heat demand strongly depends on the actual heat supply/demand. Supply distances beyond the indicated ranges we consider to be a knock-out criterion. The value of this criterion is left blank here, but it is included in the heat-demand-specific trees in Appendix A.

The last queries of the energy-related section of the tree concern the "wastewater flow rate" at the investigated in-sewer site. From a hierarchical point of view, this category certainly deserves a higher priority, as it expresses the available heat potential. However, as this aspect requires greater data collection efforts (connected PEs), it is prioritized last. Here, flow rate queries are determined in ascending order according to the values indicated in Table 2, with actual flow rates below the necessary value (demand depending) considered knock-out criteria. As flow rates are closely related to the (coverable) heat demand, values of this criterion are left blank here, but are included in the specific trees in Appendix A.

The contents of the dashed framing can be understood as intermediate results that offer a more informative character, outlining the theoretic structure of the approach but without direct practical relevance to the pre-assessment procedure. For this reason, these contents are not included in the trees for practical application summarized in Appendix A. As displayed in Table 2, the flow rate is not only closely related to the (coverable) heat demand, but to the heat extraction in the wastewater as well. This latter parameter provides a connection between the energy and wastewater sections of the approach, as higher levels of heat extraction might not only result in higher degrees of heat supply but also in more significant impacts on the inflow temperature of the WWTP.

Consequently, the first query in the wastewater section concerns the "share of total wastewater flow" at the investigated in-sewer site. According to Section 3.2.6, our approach subsequently distinguishes between two different partial flow rates (between 0.50 and the more favorable 0.25 ). 
Furthermore, it reconsiders the heat-demand-related (and thus pre-defined) wastewater flow rates from Table 2. High shares of wastewater flow at the investigated in-sewer sites (beyond 0.5) are considered a knock-out criterion if the previous queries provided a high level of heat extraction at the heat recovery site. Once more, the values of this criterion are left blank here but are included in the specific trees in Appendix A.

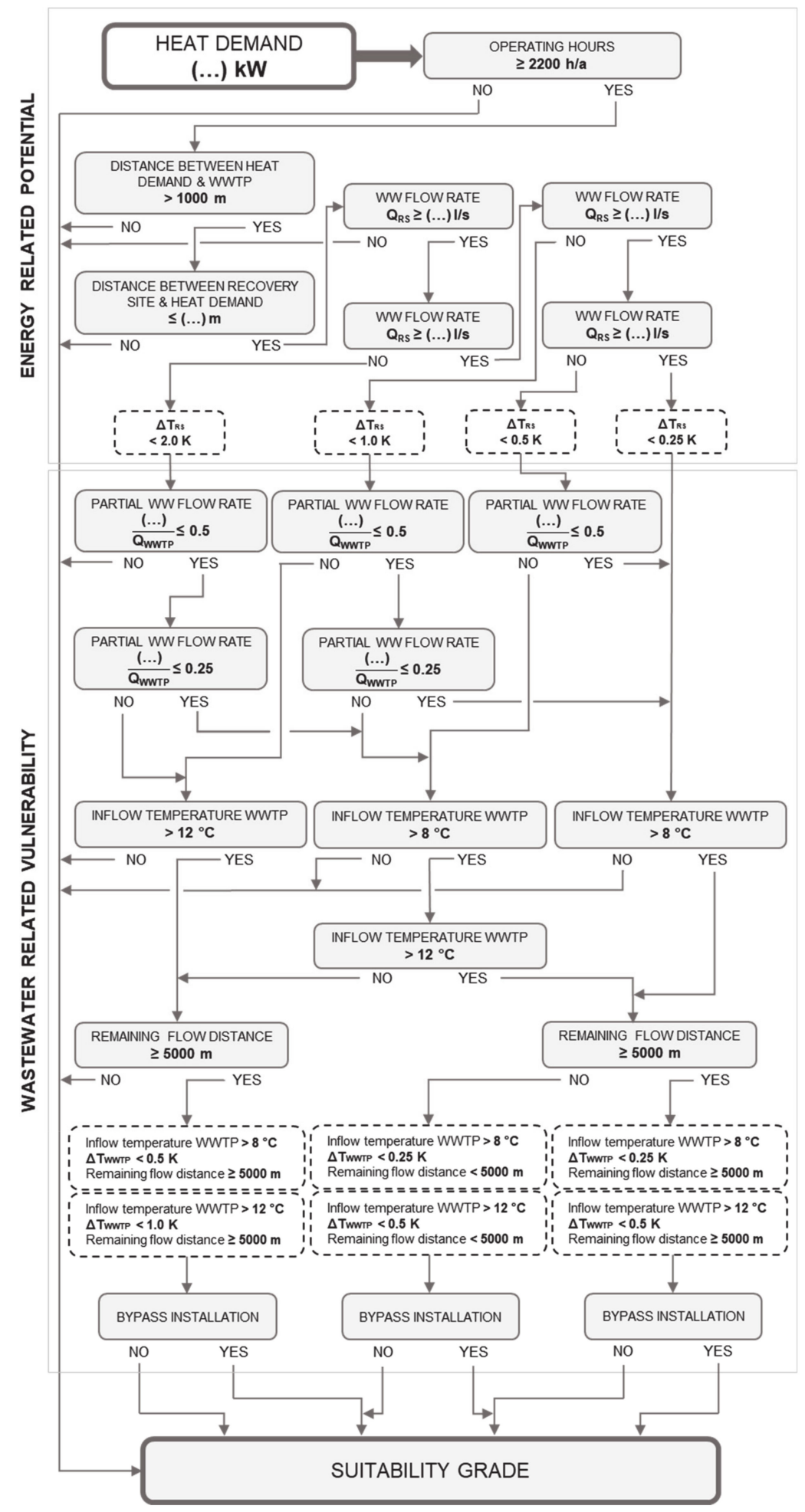

Figure 4. Overview on the theoretic relevance tree structure (own representation, based on [28]). 
The following query concerns the "wastewater temperature-related requirements/constraints". Here, the procedure basically follows the logic that higher partial flow rates subsequently require higher wastewater temperatures at the inflow of the WWTP. As our approach applies the Austrian regulatory background, one must distinguish between two thresholds. While wastewater temperatures above $12{ }^{\circ} \mathrm{C}$ are considered basically favorable, wastewater temperatures below $8^{\circ} \mathrm{C}$ are in any case seen as a knock-out criterion.

The next query addresses the "remaining flow distance" from the investigated in-sewer site to the related WWTP. Following the contents of Section 3.2.7, the distinguishing value is set to $5000 \mathrm{~m}$ here. Falling below this value might also be a (late) knock-out criterion, but usually only when all the previous queries have also provided rather poor results.

The last query of the wastewater section of the tree concerns the category of "sewer operation and maintenance". Here, the approach distinguishes the possibility of in-sewer heat recovery in a bypass solution. This is not considered to be a down-grading but not a knock-out criterion in the pre-assessment.

The dashed framing at the end part of the procedure (again) displays intermediate results that better follow the second section of the pre-assessment. They have an informative character but are not included in the trees for practical application summarized in Appendix A. At this point in the pre-assessment, a basic variety of six possible intermediate results can be derived in which those in the same column have a comparable overall suitability. The interconnections between the different categories/criteria and their impact on the pre-assessment can be summarized as follows: (i) the higher the inflow temperature at a WWTP the better; (ii) the lower the heat extraction from the wastewater the better, although higher extraction rates can be "buffered" by higher inflow temperatures; (iii) the remaining flow distance (as well as the bypass possibilities) has minimal influence.

The ending point of the entire pre-assessment approach is a statement of the investigated location on the suitability for in-sewer heat recovery, here again symbolized using bold framing. In this context, the suitability is ordinally classified based on a five-scale school grading system: (1) most suitable, (2) very suitable, (3) suitable, (4) less suitable and (5) not suitable.

It may surprise the reader that certain criteria appear more than once in the relevance tree (e.g., inflow temperature WWTP $>8{ }^{\circ} \mathrm{C}$, remaining flow distance). This is for practical reasons, as it makes the pre-assessment process clear and traceable for a specific location. However, we want to make clear that each category/criterion is only queried once during the application of the method.

\subsection{Case Study Application}

The previous section presented the theoretical set-up of the relevance tree for pre-assessing the suitability of in-sewer heat recovery sites. Now, the entire approach will be applied to the case study presented in Section 2.3 and Figure 2, respectively.

In the case study, a school building was supplied with heat extraction from wastewater. For that purpose, three possible in-sewer sites (manholes) in the immediate surroundings were identified (heat recovery sites M1, M2 and M3). Those sites made short-term in-sewer flow measurements available so that data collection efforts could be reduced, as flow rates did not have to be estimated based on the connected PEs. However, the heat demand on the school had to be derived from the heated surface area and an assumed (average) heat demand for the area. Furthermore, WWTP inflow parameters (wastewater flow rate and temperature) as well as the distance from the intended in-sewer sites to the WWTP and the school had to be collected based on a geographical information system. Table 3 summarizes the relevant data for the pre-assessment. 
Table 3. Collected data and information of the case study application (own representation).

\begin{tabular}{cccc}
\hline Approximate distance to WWTP & \multicolumn{2}{c}{$10 \mathrm{~km}$} \\
\hline Inflow temperature at the WWTP & \multicolumn{2}{c}{$8 .{ }^{\circ} \mathrm{C}$} \\
\hline Inflow rate at the WWTP & \multicolumn{3}{c}{$40 \mathrm{~L} / \mathrm{s}$} \\
\hline Assumed size of the heated floor space & \multicolumn{2}{c}{$5000 \mathrm{~m}^{2}$} \\
\hline Assumed heating demand & \multicolumn{3}{c}{$100 \mathrm{kWh} / \mathrm{m}^{2 *} \mathrm{a}$} \\
\hline Assumed operating hours of the heat recovery system & \multicolumn{3}{c}{$3000 \mathrm{~h} / \mathrm{a}$} \\
\hline Estimated total heat demand of the school building & \multicolumn{3}{c}{$170 \mathrm{~kW}$} \\
\hline Applied heat demand (selected relevance tree) & \multicolumn{3}{c}{$175 \mathrm{~kW}$} \\
\hline Heat recovery site & M1 & $\mathbf{M} 2$ & M3 \\
\hline Distance between recovery and supply site & $150 \mathrm{~m}$ & $50 \mathrm{~m}$ & $50 \mathrm{~m}$ \\
\hline In-sewer wastewater flow rate & $35 \mathrm{~L} / \mathrm{s}$ & $25 \mathrm{~L} / \mathrm{s}$ & $5 \mathrm{~L} / \mathrm{s}$ \\
\hline Remaining flow distance & $10 \mathrm{~km}$ & $10 \mathrm{~km}$ & $10 \mathrm{~km}$ \\
\hline Bypass installation possible & yes & yes & yes \\
\hline
\end{tabular}

The data collection revealed a heat demand of around $170 \mathrm{~kW}$, suggesting the application of the 175-kW relevance tree (compare Appendix A). However, further investigation could be limited to sites $\mathrm{M} 1$ and $\mathrm{M} 2$, as the flow rate of $5 \mathrm{~L} / \mathrm{s}$ at M3 was below the minimum requirement of $10 \mathrm{~L} / \mathrm{s}$ defined in Section 3.2.3. Therefore, location M3 can directly be pre-assessed as "not suitable".

As Figures 5 and 6 show, operating hours and supply distance were appropriate for both sites M1 and M2. Concerning M1 (Figure 5), the flow rate was around $35 \mathrm{~L} / \mathrm{s}$, which led to a rather unfavorable partial flow rate figure of 0.875 (based on the $35 \mathrm{~L} / \mathrm{s}$ indicated in the query box and $40 \mathrm{~L} / \mathrm{s}$ at the WWTP). Due to the fact that the inflow temperature of the WWTP was below $12{ }^{\circ} \mathrm{C}, \mathrm{M} 1$ appears "not suitable", at least for the supply of 175-kW heat. Regarding M2 (Figure 6), the flow rate was about $25 \mathrm{~L} / \mathrm{s}$, which led to a slightly more favorable partial flow rate figure of 0.4375 (based on the $17.5 \mathrm{~L} / \mathrm{s}$ indicated in the query box and $40 \mathrm{~L} / \mathrm{s}$ at the WWTP). However, the low inflow temperature of the WWTP tips the scales of M2 toward "not suitable" for the intended heat supply.

In Figures 7 and 8, the same procedure for M1 and M2, respectively, is repeated for a reduced heat demand of $150 \mathrm{~kW}$. The partial flow-rate figures, allowing conclusions regarding the possible impact of heat extraction on the inflow temperature of the WWTP, appear more promising ( 0.75 for M1 and 0.375 for M2). However, they are still too critical for the WWTP, as here again the inflow temperature query is the knock-out criterion for both sites leading to a pre-assessment result of "not suitable" for the intended heat supply.

In the next step, the intended heat supply is further decreased to $100 \mathrm{~kW}$. This is, however, a knock-out criterion for site M1, as the supply distance of 150 m exceeds the maximum of $100 \mathrm{~m}$ defined in Table $1(100 \mathrm{~m}$ per $100 \mathrm{~kW})$. Consequently, Figure 9 shows the pre-assessment process for the only remaining site, M2. Compared to the previous investigations, a partial flow rate of 0.5 here seems not very favorable. However, due to the lower heat demand, which implies a lower required level of heat extraction, the overall impression of the site is more promising. The inflow temperature of the WWTP (below $12{ }^{\circ} \mathrm{C}$ ) is again a decisive criterion. However, the long-lasting flow rate and possibility for bypass installation show that M2 appears at least potentially "suitable" as an in-sewer heat recovery site for partial supply of the school building. 


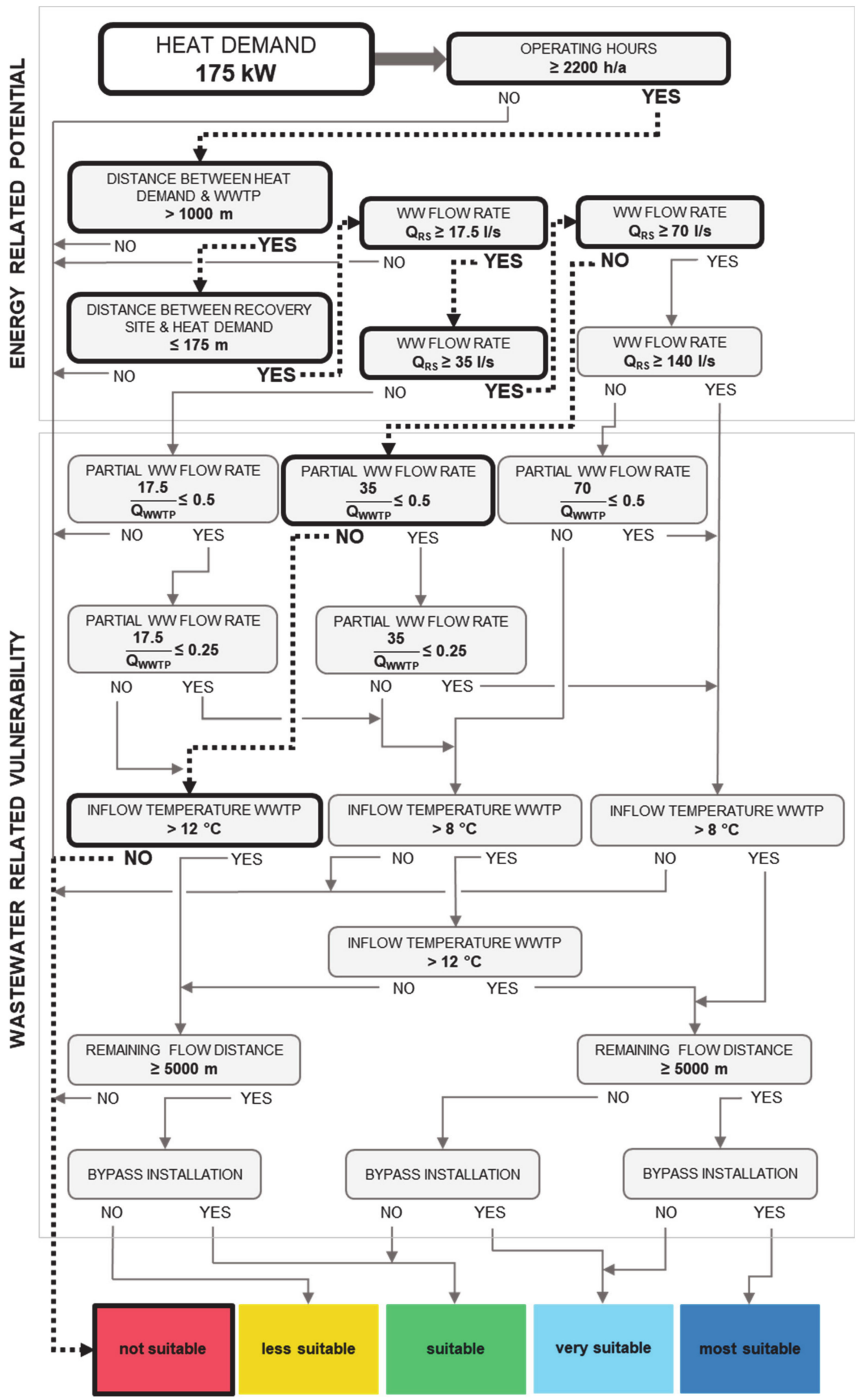

Figure 5. Pre-assessment process for heat recovery site M1 for an intended heat supply of $175 \mathrm{~kW}$ (own representation, based on [28]). 


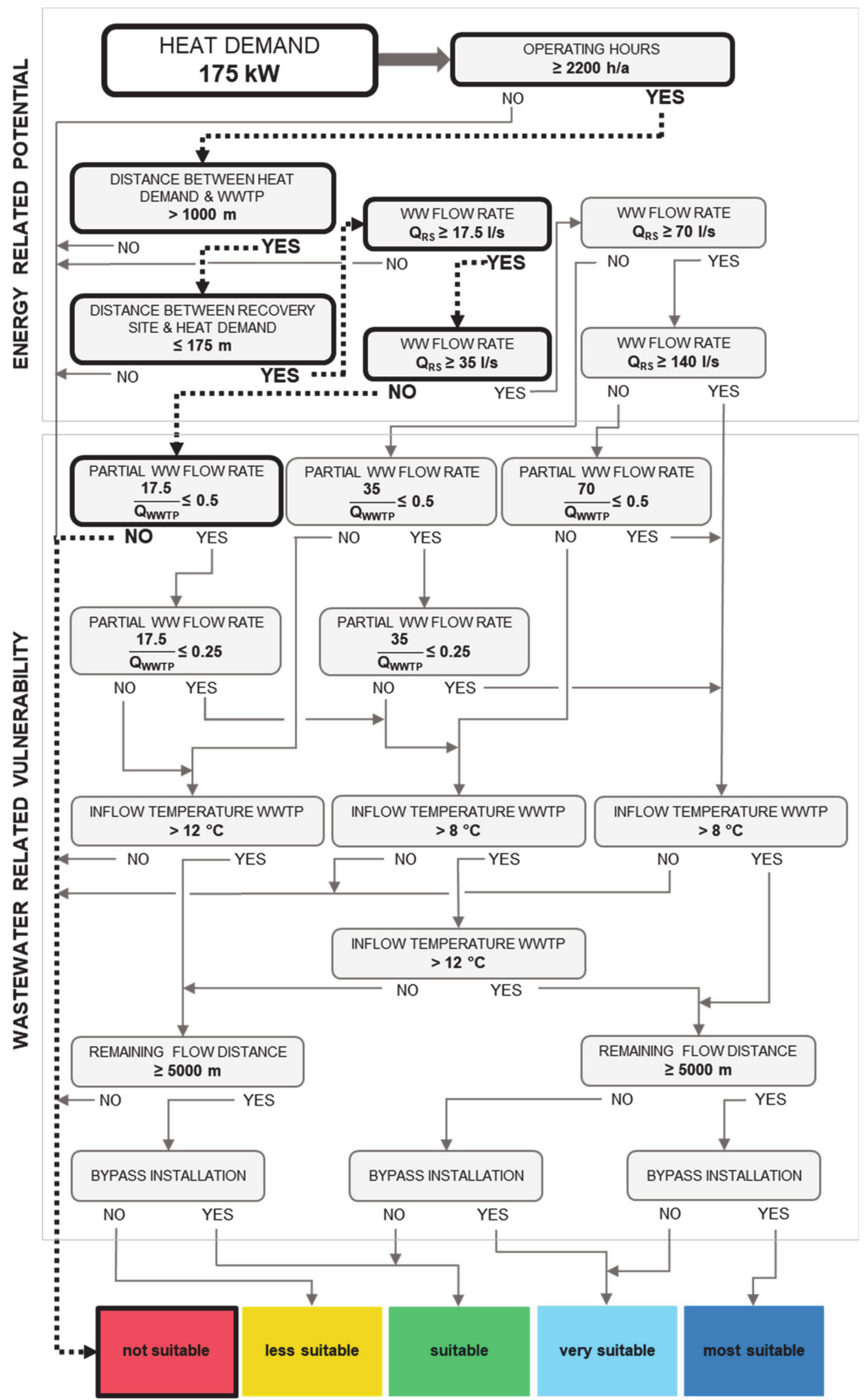

Figure 6. Pre-assessment process for heat recovery site M2 for an intended heat supply of $175 \mathrm{~kW}$ (own representation, based on [28]). 


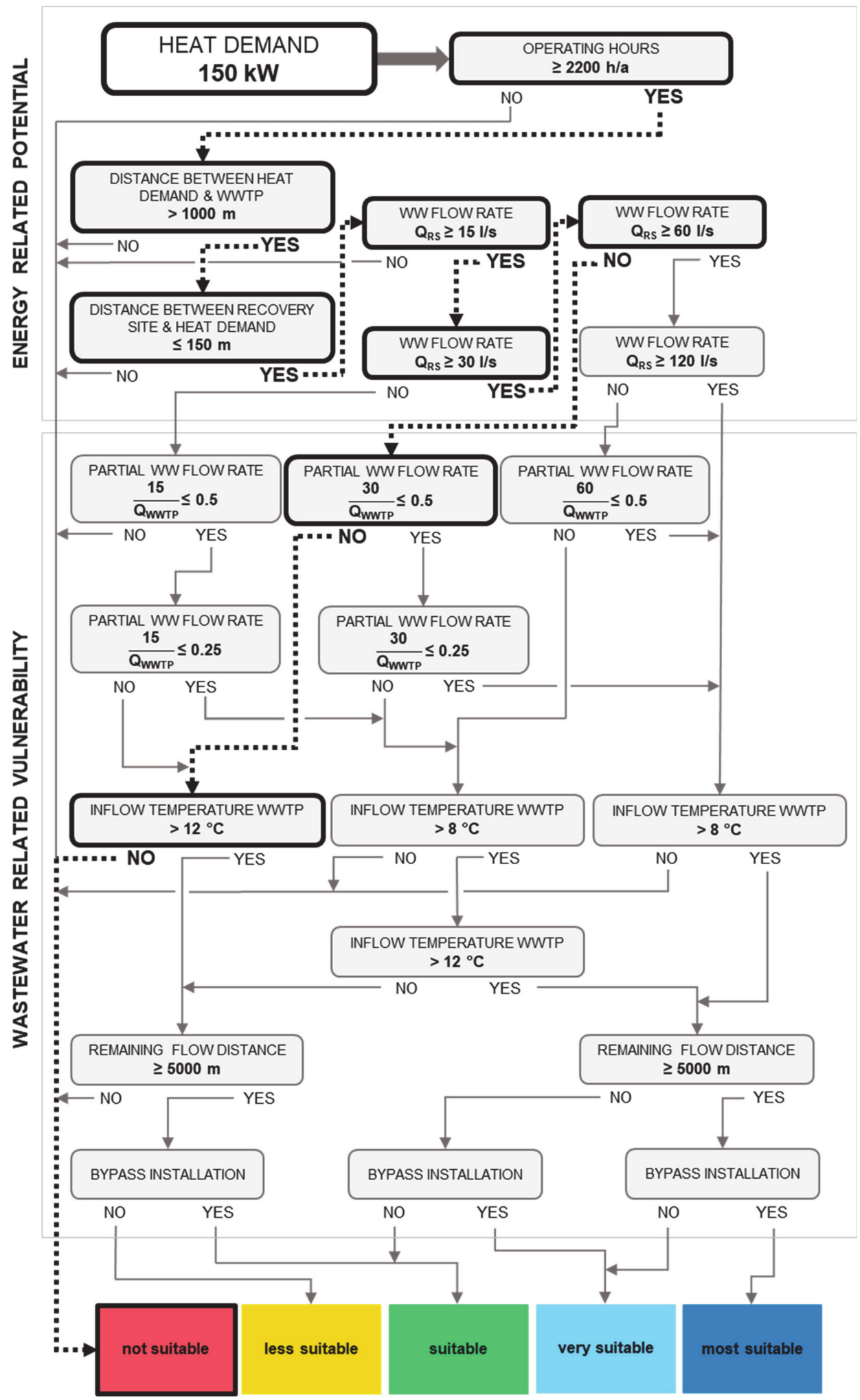

Figure 7. Pre-assessment process for heat recovery site M1 for an intended heat supply of $150 \mathrm{~kW}$ (own representation, based on [28]). 


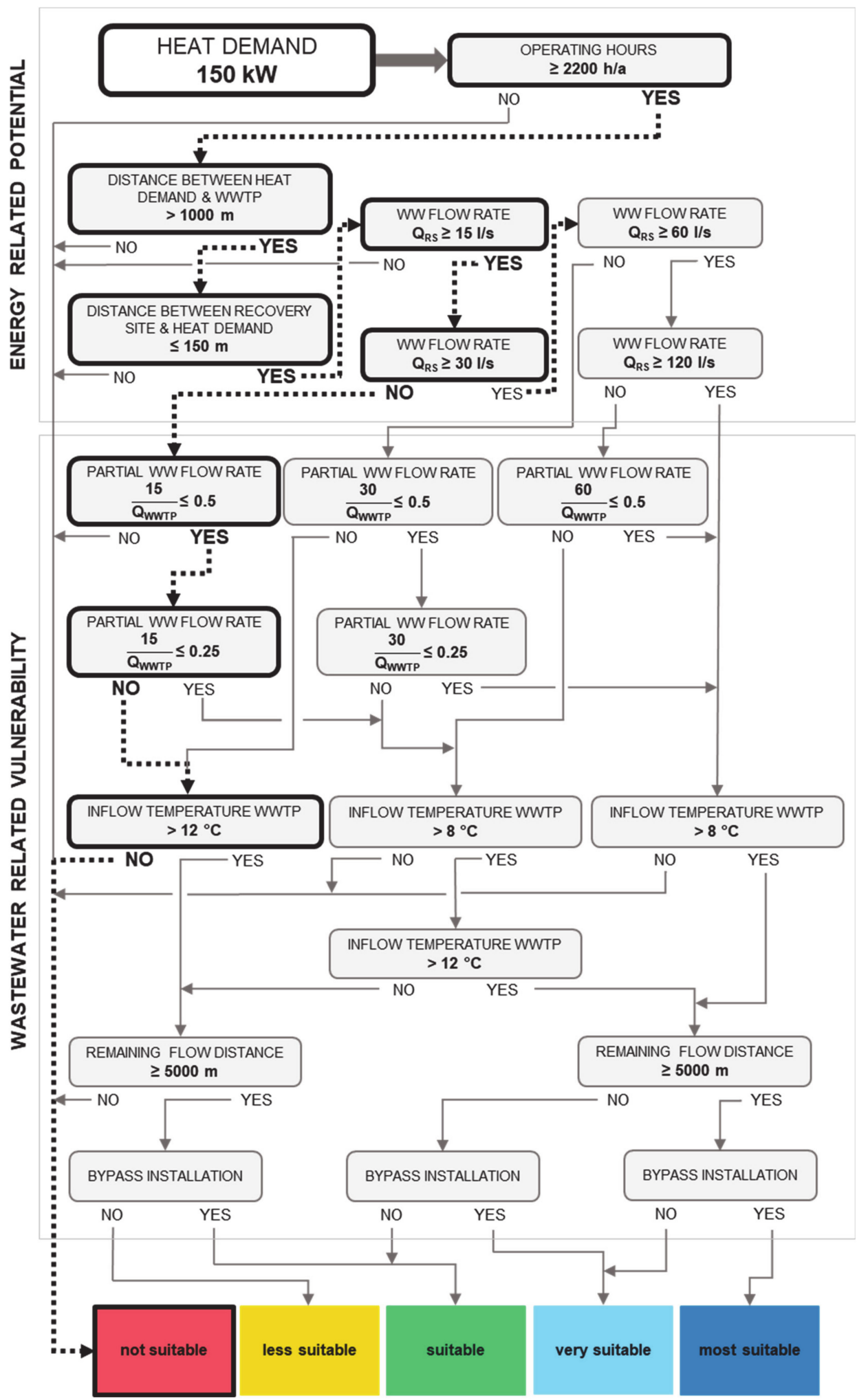

Figure 8. Pre-assessment process for heat recovery site M2 for an intended heat supply of $150 \mathrm{~kW}$ (own representation, based on [28]). 


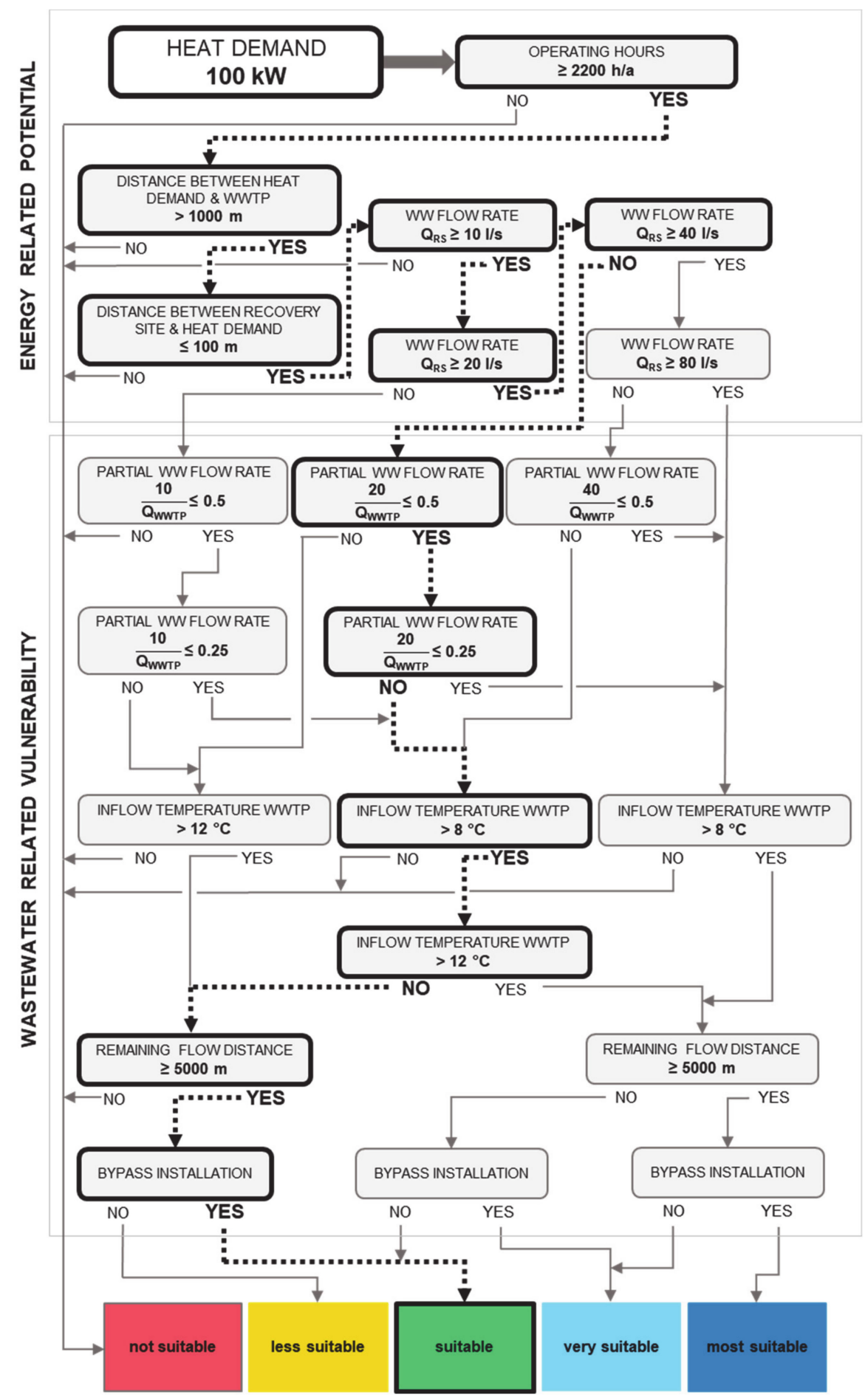

Figure 9. Pre-assessment process for heat recovery site M2 for an intended heat supply of $100 \mathrm{~kW}$ (own representation, based on [28]).

\section{Discussion}

\subsection{Interpretation of Case Study Results}

The pre-assessment presented in the previous section reveals that out of the three intended heat recovery sites, only M2 appeared "suitable" for in-sewer heat recovery. 
Concerning M3, the low wastewater flow rates, implying a rather neglectable heat potential, fulfilled a very obvious knock-out criterion. The interpretation of M1 is more complex, as the high wastewater flow rates are quite promising in principle, but the supply distance for the designated heat demand has to be considered as already critical. In addition, the wastewater flow rate at this site was in the range of the inflow rate at the WWTP, indicating a rather direct conveyance of the temperature extraction. In combination with the already quite low wastewater inflow temperatures at the WWTP, this fact also fulfills a knock-out criterion.

Regarding M2, the pre-assessment result also has to be interpreted as the site not being automatically "suitable" for in-sewer wastewater heat recovery, but with potential for a deeper look into the site-specific conditions. As previously mentioned, for getting a better impression of the long-term heat-potential measurement of wastewater flow and temperature during the heating season is recommended (at least representative daily curves for the coldest month). The only measurements detailed allow concrete propositions for the available heat potential. In addition, the flow and temperature data collected at the intended in-sewer site have to overlap with corresponding curves from the influent of the WWTP (especially as the inflow temperature appears to be very close to the threshold value of an accepted level). This direct comparison will allow more reliable statements on the potential impact of in-sewer heat extraction on inflow temperature. If the measurement campaign provides promising results, the next step would be to carry out a feasibility study.

In the context of the investigated school, the feasibility study would have to address a few issues. Firstly, as the available in-sewer heat potential might only cover a part of the school's total heat demand, wastewater heat could be used to cover a base load demand, although for peak demand an additional heat source would be necessary. This peak supply system could also be used as a backup in case the heat extraction from wastewater had to be suspended due to underrunning a minimum wastewater temperature at the inflow of the WTTP. Secondly, a combined supply of heat and cool would increase the operating hours of the wastewater heat supply system (heat pump) and thus its economic efficiency. Thirdly, photovoltaic installations on the school's roof area could (partly) provide the required electricity for the heat pump. This might also have positive effects on the economic feasibility of the intended installations.

\subsection{Practicability of the Proposed Method}

The proposed method for pre-assessing in-sewer heat recovery sites proved its general practicability in the case study application. Due to the fact that the proposed method is based on commonly available information, data collection is not a very challenging task. Subsequent queries of different thematic categories/criteria in the relevance tree allow a quick and conclusive identification of promising locations by concurrently providing a deeper understanding of site-specific conditions and the interactions in the investigated framework.

Although the handling of relevance tree(s) is very easy and straightforward, a quick check of specific (knock-out) criteria can be recommended as a preliminary step. From our experience, the following three (out of our eight categories/criteria) were very appropriate in this context: (i) do heat demand and supply distance match (Table 1); (ii) do heat demand and flow rate match (Table 2); and (iii) are inflow temperatures at the WWTP beyond treatment-related thresholds. A short verification of these aspects immediately reveals a weak point could make the application of the entire pre-assessment procedure more than questionable. However, in this context one should keep in mind that a partial supply of heat demand (in combination with another source) might also be an option. In such a case, quick check parameters should be adapted accordingly.

Finally, one has to consider that the focus of the presented study was only on one specific heat extraction/supply site. Actually, the suggested approach also permits system-wide investigations. If a wastewater operator intends to promote in-sewer heat recovery, the approach could be used to "proactively" identify promising sites in the wastewater system. With knowledge of the location of potential heat sources, an energy supplier could "reactively" pre-assess the suitability of suggested 
sites by considering relevant energy-related boundary conditions (e.g., heat demand, supply distance). In contrast, an energy supplier could "proactively" identify possible heat sources in the vicinity of an intended heat consumption point. With knowledge about the intended in-sewer heat recovery site(s), the wastewater utility could "reactively" pre-assess its suitability in consideration of wastewater-related boundary conditions (e.g., partial flow rate, inflow temperature at the WWTP). Consequently, the suggested approach provides quick and comprehensive information whether (follow-up) feasibility studies make sense or not. Furthermore, it certainly helps to improve targeted communication between stakeholders (energy and wastewater utilities, municipalities).

\subsection{Strengths and Weaknesses of the Approach}

As indicated in the introduction section of this article, recent literature has highlighted two approaches for predicting/evaluating the possible impacts of in-sewer heat recovery on the inflow temperature of a WWTP: the simple to apply (but less significant) alligation alternate, or more accurate (but data-intensive) modelling approaches. The proposed pre-assessment method can complement the existing concepts by filling the gap between significance and practicability. However, it does not only analyze the possible impacts of in-sewer wastewater heat recovery, but provides a broader view on the entire system by integrating energy- and wastewater-related perspectives. Consequently, it provides more information compared to the common alligation alternate with minimal additional data collection efforts. The pre-assessment helps to identify the most promising in-sewer sites that are worth investigating in more detail. The subsequent evaluations could include the implementation of a mathematical model. Pre-assessment results support a targeted model set-up, as they provide an initial outline of the most interesting and critical parts of the entire system.

At the same time, one has to always keep in mind that (in-sewer) wastewater heat recovery is a very complex and interactive task. To ensure its practicability, the proposed pre-assessment procedure incorporates certain simplifications. First of all, as the pre-assessment results in an ordinal ranking of the investigated site(s), the query structure follows a simple yes-no approach based on sharp threshold values for the different thematic categories/criteria (depending on the applied heat demand). Consequently, the pre-assessment is rather strict, even if a value is only slightly below the defined target. Secondly, an important but difficult parameter to obtain is the wastewater flow rate at the intended heat recovery site. An estimation based on the connected PEs is always possible; however, per capita water consumption data can vary locally and usually does not take infiltration water into account. Wrong estimations of wastewater flow can be very misleading. Therefore, a consultation with the local wastewater utility is recommended in order to verify flow estimations. Short-term in-sewer measurements can also be supportive (as in the presented case study). Thirdly, the wastewater flow rate is also important in another context-it implies the available heat potential in the wastewater, and thus is strongly related to the heat demand and he possible heat extraction (cooling) of the wastewater (see Table 2). To cover a broad variety of possible applications (heat demands), we consider a rather wide range of wastewater flows. However, the ordinal background of our approach implies that all flow rates within a certain range are considered equal, irrespective of their actual (cardinal) value. This approach incorporates a certain imprecision, which we accept to keep the number of queried criteria (and thus the complexity) of the (relevance) tree at a manageable level. Finally, the partial wastewater flow rate is an important criterion by which to estimate the possible impact of in-sewer heat recovery on the wastewater temperature at the inlet of a WWTP. For its calculation, the related query in the relevance tree only demands the inflow of the WWTP $\left(Q_{W W T P}\right)$, as the flow rate at the heat recovery site $\left(\mathrm{Q}_{\mathrm{RS}}\right)$ is not defined by the actual value but by the applied threshold value from Table 2 . This simplification implies a certain inaccuracy, but keeps the relevance tree simple and manageable. Furthermore, it guarantees the consistency between heat demand, in-sewer flow rate and expected heat-extraction (according to Table 2) in the different relevance trees.

Summarizing the above, the suggested approach provides a pre-assessment of possible in-sewer heat recovery sites and not a detailed and final evaluation. Being aware of the methodological and 
technical constraints of the procedure certainly can support a proper interpretation of the obtained suitably grades. Furthermore, the currently applied criteria/threshold values are primarily based on contents of the applied materials from German-speaking countries. An adaption of the pre-assessment procedure/relevance trees considering specific boundary conditions and experiences of alternative regions is possible and recommended. Future enhancements of the concept might also include not only a heating, but also a cooling demand, as well as additional categories and criteria (e.g., minimum cross-section of intended sewer segments).

\section{Conclusions}

Wastewater as a source of locally available and renewable heat can certainly be a valuable contribution to the ongoing transition of energy systems for counteracting global warming. In this context, heat extraction in sewer systems implies short heat supply distances and thus promising economic benefits from an energy perspective. However, one has to keep in mind that from a wastewater perspective the primary goal of wastewater systems is public health, urban flood protection and water pollution control. Consequently, in-sewer heat recovery must neither impede proper sewer operation and maintenance nor (temperature sensitive) treatment processes in a WWTP. From an integrated point of view, both perspectives (climate and water protection) serve the superior goal of environmental protection. As a consequence, both aspects should not be considered mutually exclusive but inclusive.

This article suggests an approach for pre-assessing potential in-sewer heat recovery sites that addresses both perspectives and aims to close the gap between the currently available approaches that are either rather simple to apply but less significant, or very accurate but less practical. According to the research questions formulated in the introduction section, this article presents thematic categories to describe the energy-related potential (heat demand, supply distance, (dry weather) wastewater flow rate and operating hours) as well as the wastewater-related vulnerability (wastewater temperature requirements/constraints, share of total wastewater flow, remaining flow distance and sewer operation and maintenance) of an intended site. Furthermore, (measurable) criteria are defined, allowing a qualitative and/or quantitative evaluation of each thematic category. Finally, all criteria/categories are joined in the form of a relevance tree to provide a clear working flow for the pre-assessment procedure.

The theoretical background of the work is based on literature from German-speaking countries that already have notable experience and expertise in this field. From a practical point of view, the introduced approach was tested in an Austrian case study. It proved its informative value along with an easy and simple application. Although developed and tested under relatively "local" boundary conditions, we believe that the presented concept can serve as an applicable guidance and template for pre-evaluating potential in-sewer heat recovery from an integrated perspective at any conventional (combined or separated) sewer system. The article does not only contain a detailed description of pre-assessment categories and criteria in the main text, but also a summary of exemplary relevance trees for suggested heat supplies (heat demands), summarized in Appendix A. This information can support practitioners (e.g., wastewater utilities, energy suppliers, engineering offices, municipal departments) around the world to develop tailor-made solutions that consider their site-specific contexts and demands. Finally, our approach should help facilitate the screening of potential in-sewer heat recovery sites, and make the decision-making behind subsequent feasibility studies more transparent. Future wastewater management will still serve its primary duties in regard to water protection and pollution control. It might also provide additional benefits in regard to climate protection. This article intends to support this development.

Author Contributions: Conceptualization, F.H. and F.K.; methodology, F.H., G.N. and F.K.; validation, F.H. and F.K.; formal analysis, F.H.; investigation, F.H. and F.K.; data curation, F.H.; writing —original draft preparation, F.H., G.N. and F.K.; writing - review and editing, T.E.; visualization, F.H.; supervision, T.E.; project administration, F.K. All authors have read and agreed to the published version of the manuscript.

Funding: This research received no external funding. 
Acknowledgments: This article is based on the first author's master thesis quoted as literature source [28]. We thank the local consultant [25], the local wastewater utility [26], and the heat exchanger manufacturer [27] for data provision as well as the reviewers for their time to review our manuscript and their valuable comments. The open access funding was provided by BOKU Vienna Open Access Publishing Fund.

Conflicts of Interest: The authors declare no conflict of interest.

\section{Appendix A}

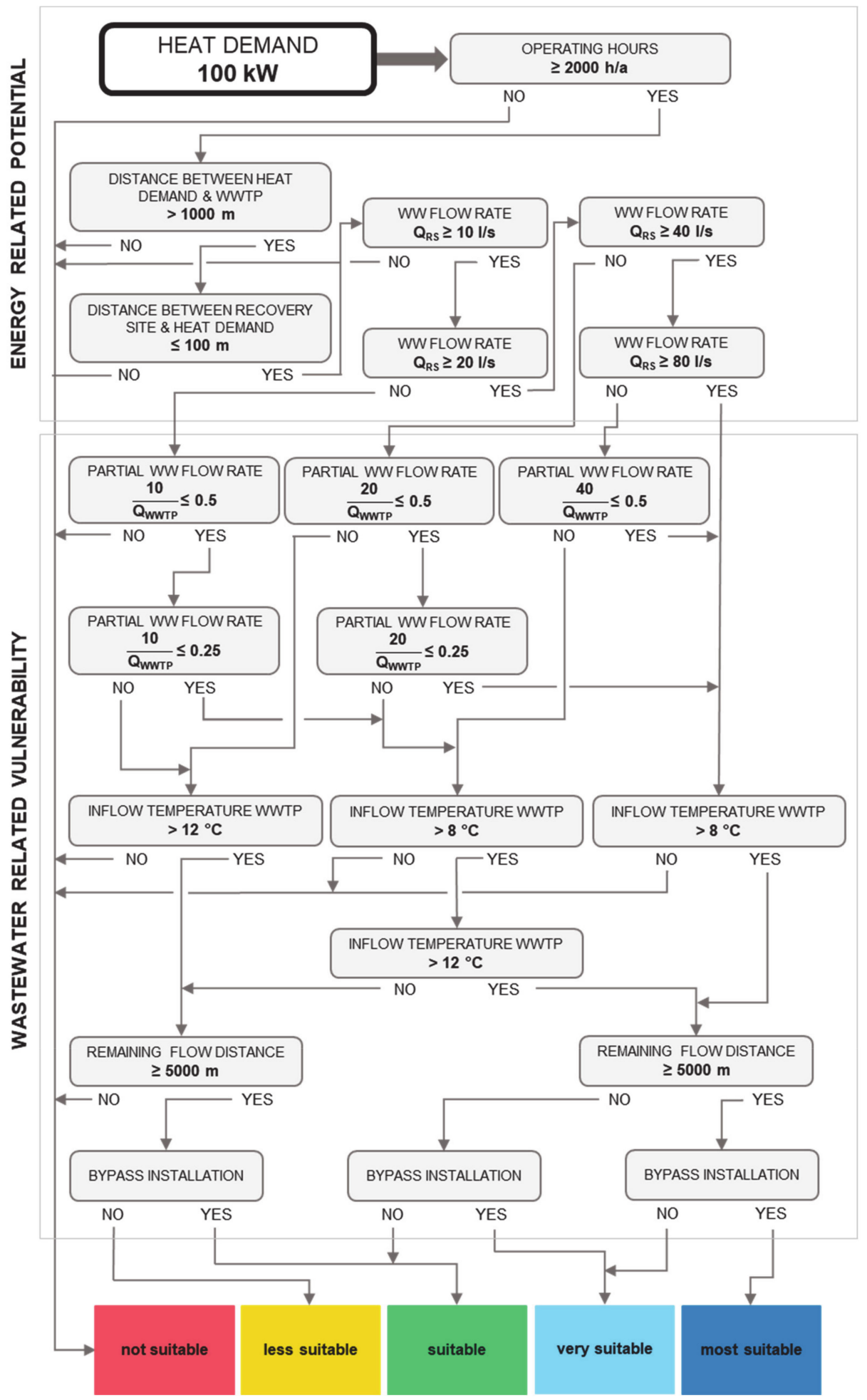

Figure A1. Relevance tree for an intended heat supply of $100 \mathrm{~kW}$ (own representation, based on [28]). 


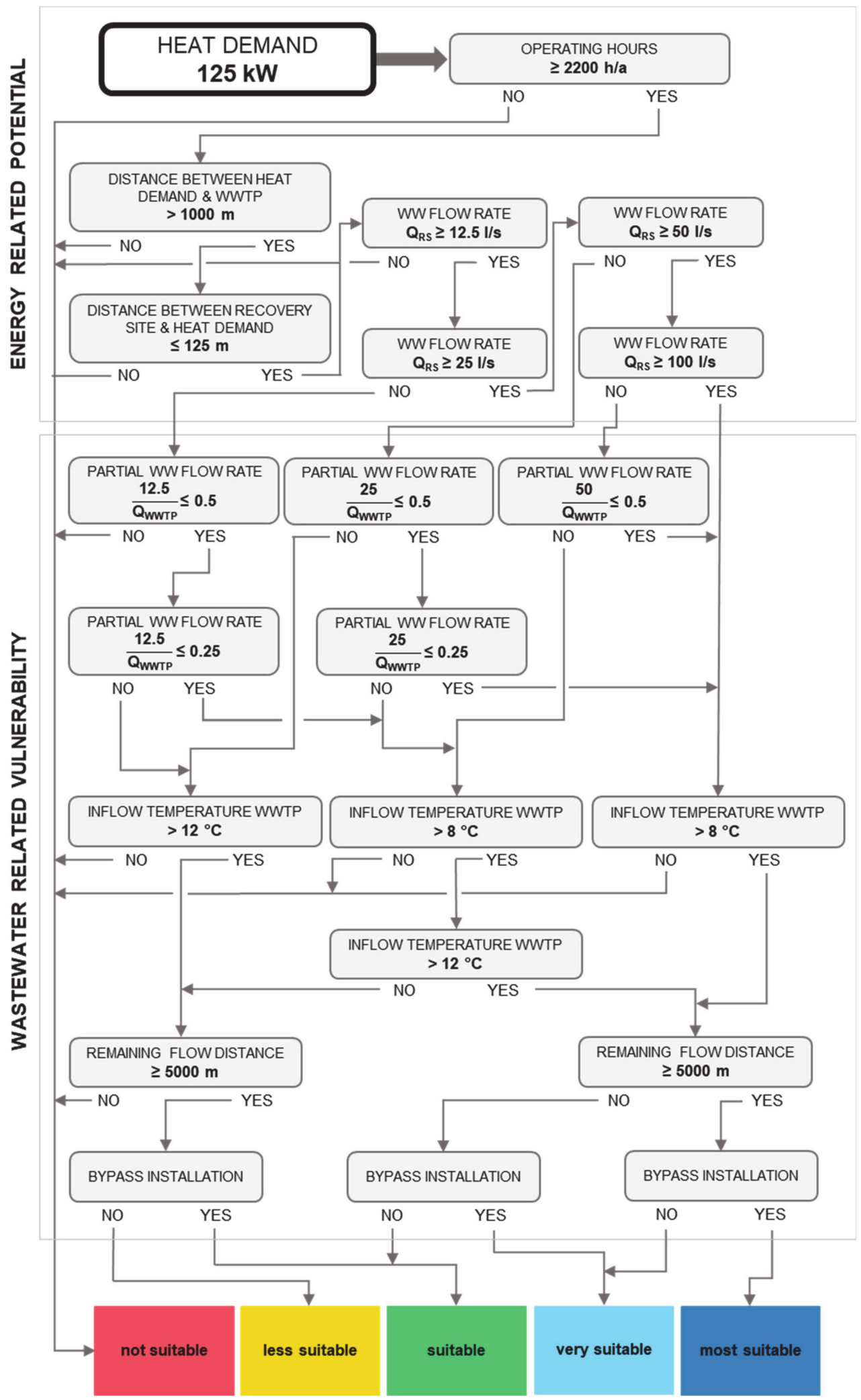

Figure A2. Relevance tree for an intended heat supply of $125 \mathrm{~kW}$ (own representation, based on [28]). 


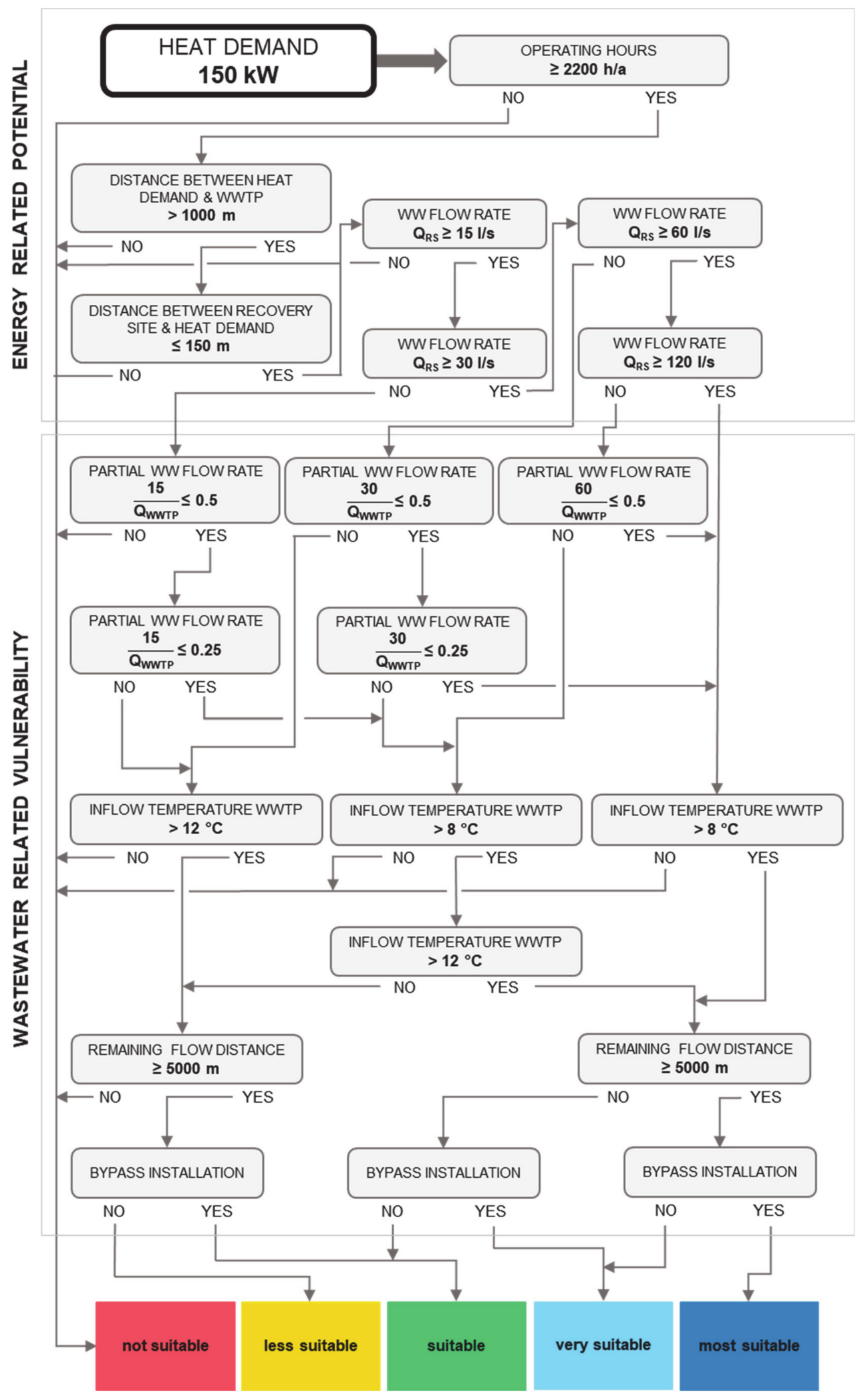

Figure A3. Relevance tree for an intended heat supply of $150 \mathrm{~kW}$ (own representation, based on [28]). 


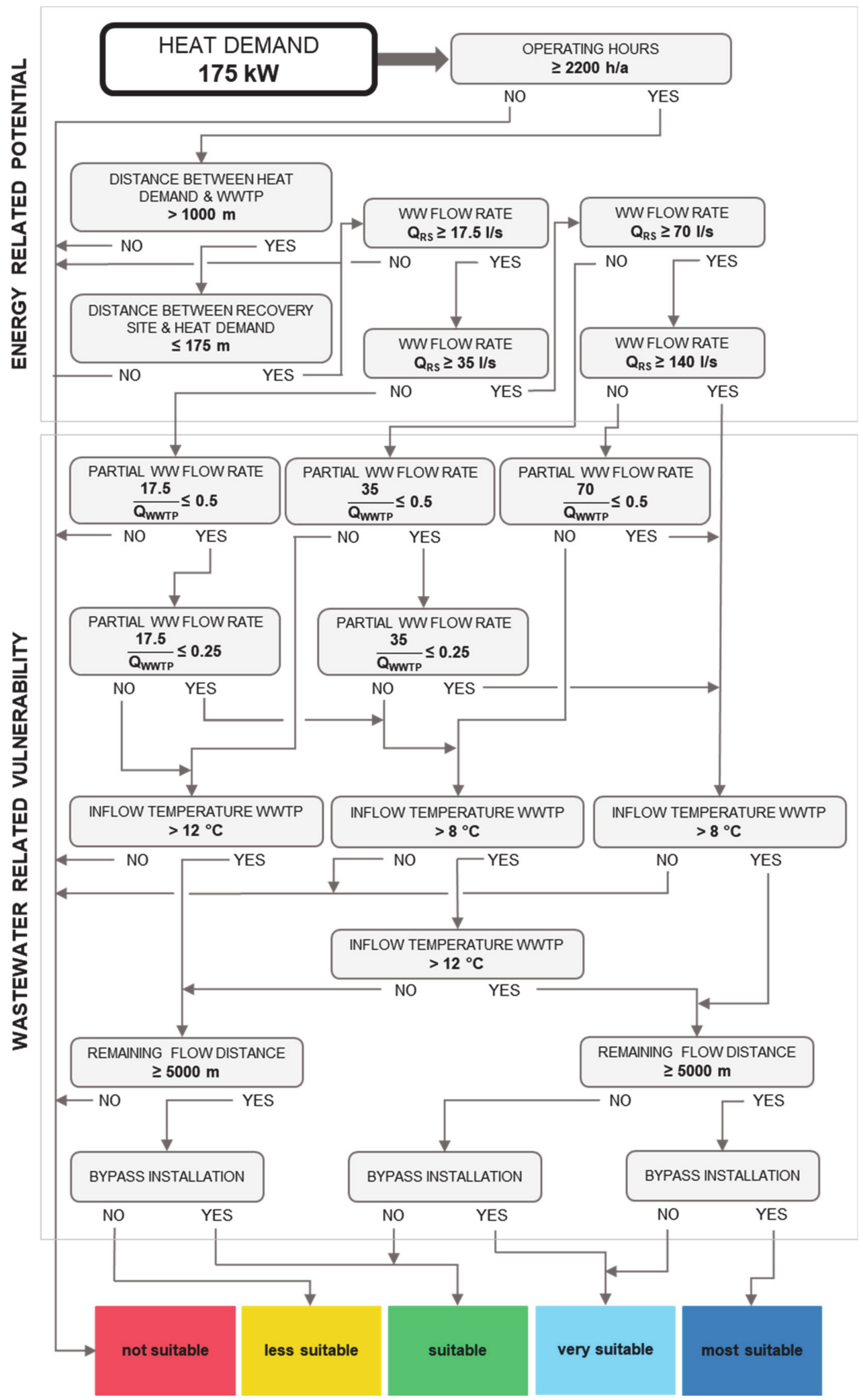

Figure A4. Relevance tree for an intended heat supply of $175 \mathrm{~kW}$ (own representation, based on [28]). 


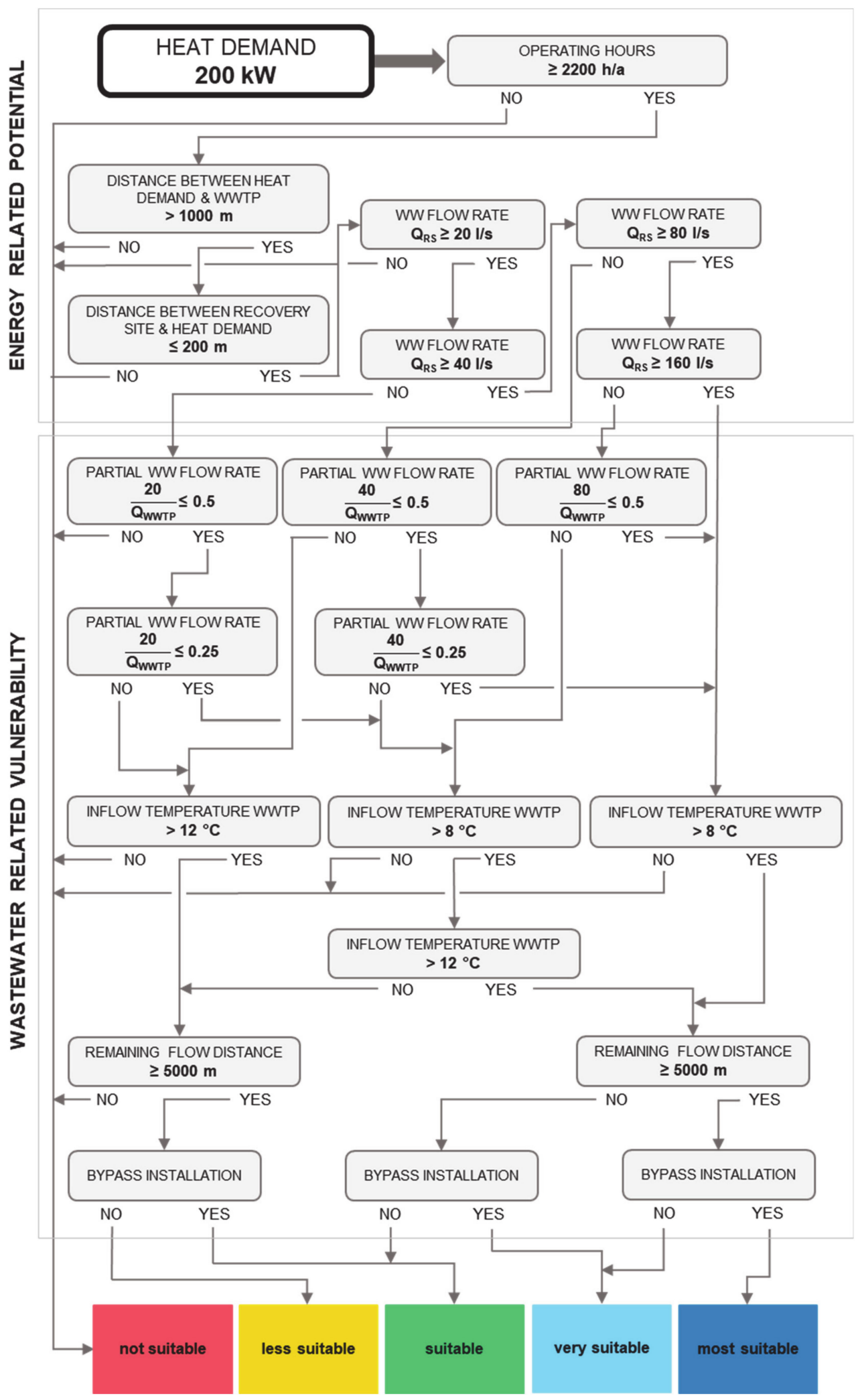

Figure A5. Relevance tree for an intended heat supply of $200 \mathrm{~kW}$ (own representation, based on [28]). 


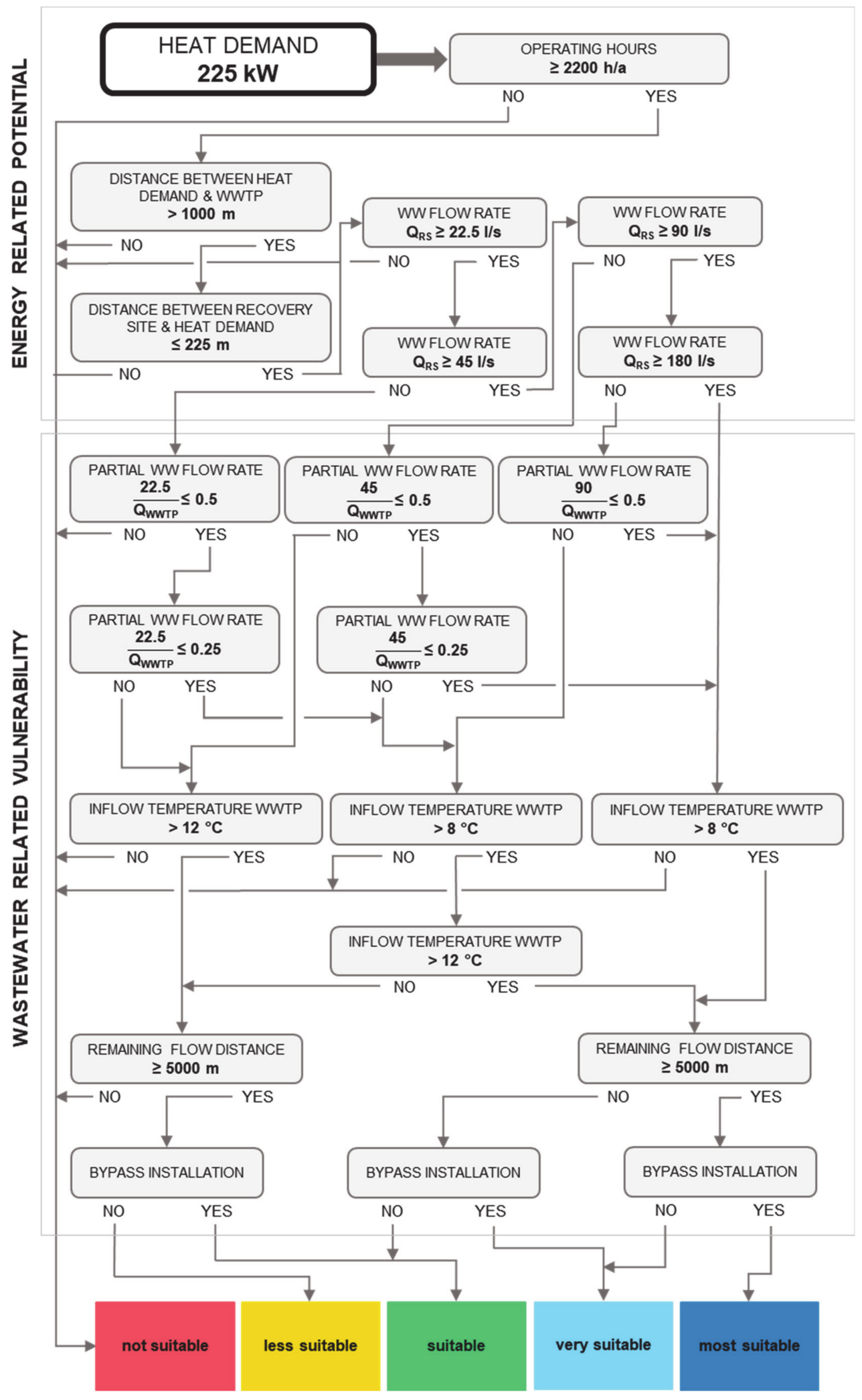

Figure A6. Relevance tree for an intended heat supply of $225 \mathrm{~kW}$ (own representation, based on [28]). 


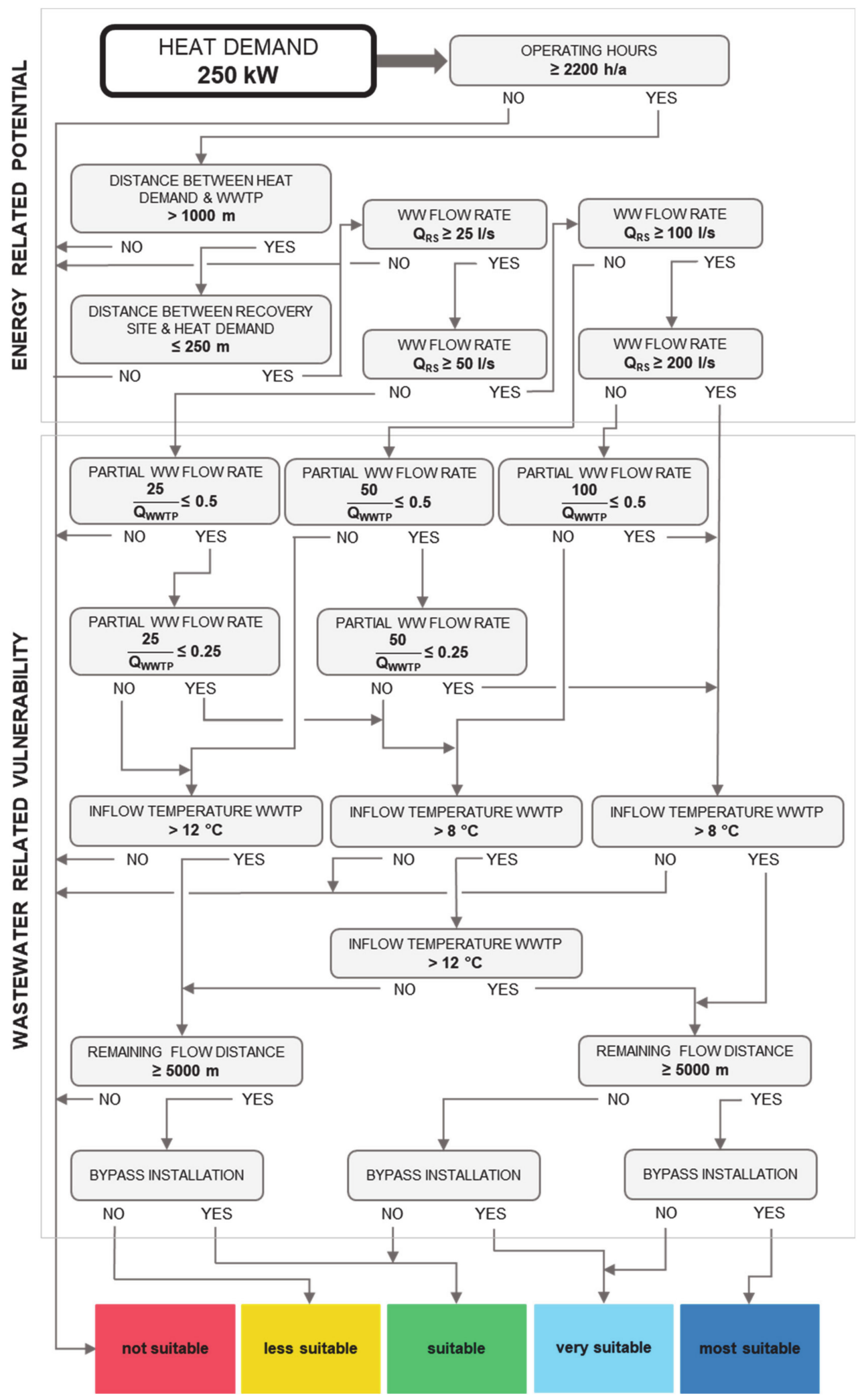

Figure A7. Relevance tree for an intended heat supply of $250 \mathrm{~kW}$ (own representation, based on [28]). 




Figure A8. Relevance tree for an intended heat supply of $275 \mathrm{~kW}$ (own representation, based on [28]). 


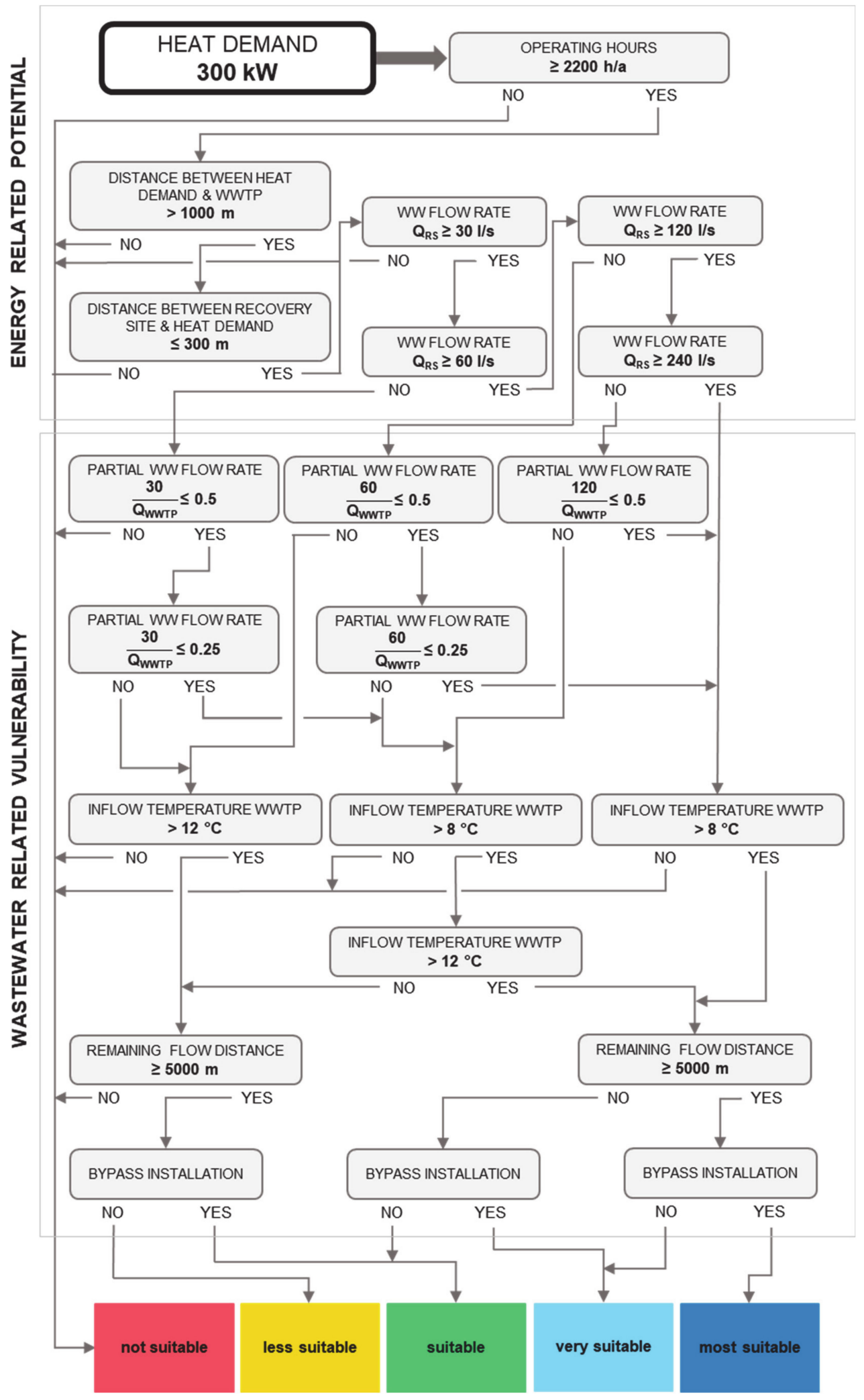

Figure A9. Relevance tree for an intended heat supply of $300 \mathrm{~kW}$ (own representation, based on [28]). 


\section{References}

1. United Nations. Transforming our World: The 2030 Agenda for Sustainable Development; United Nations: New York, NY, USA, 2015; Resolution adopted by the General Assembly on 25 September 2015; A/RES/70/1.

2. European Commission. 2030 Climate \& Energy Framework. Available online: https://ec.europa.eu/clima/ policies/strategies/2030_en (accessed on 14 October 2020).

3. European Commission. Communication from the Commission to the European Parliament, the Council, the European Economic and Social Committee and the Committee of the Regions-An EU Strategy on Heating and Cooling; European Commission: Brussels, Belgium, 2016.

4. European Parliament and the Council. Directive (EU) 2018/2001; Promotion of the use of Energy from Renewable Sources (recast); European Parliament and the Council: Brussels, Belgium, 2018.

5. Schmid, F. (s.a.): Sewage Water: Interesting Heat Source for Heat Pumps and Chillers. In Proceedings of the 9th International IEA Heat Pump Conference, Zürich, Switzerland, 20-22 May 2008.

6. Elías-Maxil, J.A.; van Der Hoek, J.P.; Hofman, J.; Rietveld, L. Energy in the urban water cycle: Actions to reduce the total expenditure of fossil fuels with emphasis on heat reclamation from urban water. Renew. Sustain. Energy Rev. 2014, 30, 808-820. [CrossRef]

7. Neugebauer, G.; Kretschmer, F.; Kollmann, R.; Narodoslawsky, M.; Ertl, T.; Stoeglehner, G. Mapping thermal energy resource potentials from wastewater treatment plants. Sustainability 2015, 7, 12988-13010. [CrossRef]

8. Hao, X.; Li, J.; van Loosdrecht, M.C.M.; Han, J.; Liu, R. Energy recovery from wastewater: Heat over organics. Water Res. 2019, 161, 74-77. [CrossRef] [PubMed]

9. Frijns, J.; Hofman, J.; Nederlof, M. The potential of (waste)water as energy carrier. Energy Convers. Manag. 2013, 64, 357-363. [CrossRef]

10. Culha, O.; Gunerhan, H.; Biyik, E.; Ekren, O.; Hepbasli, A. Heat exchanger applications in wastewater source heat pumps for buildings: A key review. Energy Build. 2015, 104, 215-232. [CrossRef]

11. Wanner, O.; Panagiotidis, V.; Clavadetscher, P.; Siegrist, H. Effect of heat recovery from raw wastewater on nitrification and nitrogen removal in activated sludge plants. Water Res. 2005, 39, 4725-4734. [CrossRef] [PubMed]

12. European Standard EN 752:2017. Drain and Sewer Systems Outside Buildings-Sewer System Management; European Committee for Standardization: Brussels, Belgium, 2017.

13. Kretschmer, F.; Simperler, L.; Ertl, T. Analysing wastewater temperature development in a sewer system as a basis for the evaluation of wastewater heat recovery potentials. Energy Build. 2016, 128, 639-648. [CrossRef]

14. Dürrenmatt, D.; Wanner, O. A mathematical model to predict the effect of heat recovery on the wastewater temperature in sewers. Water Res. 2014, 48, 548-558. [CrossRef] [PubMed]

15. Elías-Maxil, J.A.; Hofman, J.; Wols, B.; Clemens, F.; van der Hoek, J.P.; Rietveld, L. Development and performance of a parsimonious model to estimate temperature in sewer networks. Urb. Water J. 2017, 14, 829-838. [CrossRef]

16. Abdel-Aal, M.; Mohamed, M.; Smits, R.; Abdel-Aal, R.E.; de Gussem, K.; Schellart, A.; Tait, S. Predicting wastewater temperatures in sewer pipes using abductive network models. Water Sci. Technol. 2015, 71, 89-96. [CrossRef] [PubMed]

17. Schlagbauer, P. Thermische Energiegewinnung aus Abwasser-Entwicklung eines Temperaturmodells für SWMM (Thermal Energy Recovery from Wastewater-Development of a Temperture Model for SWMM). Master's Thesis, Technical University of Graz, Graz, Austria, 2018.

18. Wärff, C.; Arnell, M.; Sehlén, R.; Jeppson, U. Modelling heat recovery potential from household wastewater. Water Sci. Technol. 2020, 81, 1597-1605. [CrossRef] [PubMed]

19. Golzar, F.; Nilsson, D.; Martin, V. Forecasting wastewater temperature based on artificial neural network (ANN) technique and Monte Carlo sensitivity analysis. Sustainability 2020, 12, 6386. [CrossRef]

20. Fürst, D.; Scholles, F. Handbuch Theorien und Methoden der Raum- und Umweltplanung. In Handbook on Theories and Methods in Spatial and Environmental Planning; Rohn: Dortmund, Germany, 2008.

21. Stöglehner, G. Grundlagen der Raumplanung 1-Theorien, Methoden, Instrumente (Basics of Spatial Planning 1-Theories, Methods, Instruments); Stöglehner, G., Ed.; Facultas: Vienna, Austria, 2019; p. 332. 
22. Koch, M.; Nietlisbach, A.; Känel, B.; Calderoni, M.; Wille, B.; Müller, R.; Bretscher, P.; Wanner, O.; Siegrist, H.; Peter, A.; et al. Heizen und Kühlen mit Abwasser_Leitfaden für die Planung, Bewilligung und Realisierung von Anlagen zur Abwasserenergienutzung (Heating and Cooling with Wastewater-guideline for Planning, Approving and Realising Energetic use of Wastewater); Amt für Abfall, Wasser, Energie und Luft: Zürich, Switzerland, 2010.

23. Project Team „Abwasserenergie“. Abwasserenergie-Die Kläranlage als regionale Energiezelle (Wastewater Treatment Plants as Regional Energy Cells). Available online: http://www.abwasserenergie.at/fileadmin/ energie_aus_abwasser/user_upload/Broschuere_Abwasserenergie_2017.pdf (accessed on 15 October 2020).

24. Merkblatt DWA-M114 Abwasserwärmenutzung (Wastewater Heat Recovery); German Water Association: Hennef, Germany, 2020.

25. Wiedemann, R. Spot Check on In-sewer Wastewater Flows and Temperatures at Three Different In-sewer Sites Carried out by Rabmer GreenTech, Written communication from 14 July 2020, provided by the local wastewater utility.

26. Local wastewater utility. Average Wastewater Flows and Temperatures at the Local Wastewater Treatment Plant, Oral communication on 28 September 2020.

27. Zeus, R. Erschließungslängen bei der Versorgung mit Abwasserwärme aus Kanalisationsanlagen-Erfahrungen aus Projektumsetzungen der UHRIG Energie GmbH. (Supply Distances of In-sewer Wastewater Heat Recovery-practical Experiences of UHRIG Energie GmbH), Written communication from 23 April 2020.

28. Huber, F. Vorbewertung eines Standortes zur Abwasserwärmenutzung im Kanal aus energie-und abwasserwirtschaftlicher Sicht (Pre-assessment of an In-sewer Heat Recovery Site from Energy and Wastewater Perspectives). Master's Thesis, University of Natural Resources and Life Sciences, Vienna, Austria, 2020.

29. AEVkA. Verordnung des Bundesministers für Land-und Forstwirtschaft über die Begrenzung von Abwasseremissionen aus Abwasserreinigungsanlagen für Siedlungsgebiete (Order of the Federal Minister of Agriculture, Forestry, Environment and Water Management concerning Limitations of Wastewater Emissions from Wastewater Treatment Plants for Settlement Areas), BGBl. Nr. 210/1996 idF. BGBl. II Nr. 392/2000, Vienna.

30. Bischofsberger, W.; Seyfried, C.F. Wärmeentnahme aus Abwasser (Heat Extraction from Wastewater); Lehrstuhl und Prüfamt für Wassergütewirtschaft und Gesundheitsingenieurwesen der Technischen Universität München: Garching, Germany, 1984.

31. Cipolla, S.S.; Maglionico, M. Heat recovery from urban wastewater: Analysis of the variability of flow rate and temperature. Energy Build. 2014, 69, 122-130. [CrossRef]

32. Wanner, O.; Delavy, P.; Eugster, J.; Panagiotidis, V.; Siegrist, H. Wärmerückgewinnung aus Abwassersystemen. Schlussbericht (Heat Recovery from Wastewater Systems. Final Report); By order of Bundesamt für Energie: Dübendorf, Switzerland, 2004.

Publisher's Note: MDPI stays neutral with regard to jurisdictional claims in published maps and institutional affiliations.

(C) 2020 by the authors. Licensee MDPI, Basel, Switzerland. This article is an open access article distributed under the terms and conditions of the Creative Commons Attribution (CC BY) license (http://creativecommons.org/licenses/by/4.0/). 